\title{
Effects of Cooling Temperatures via Thermal K2P Channels on Regeneration of High-Frequency Action Potentials at Nodes of Ranvier of Rat A $\beta$-Afferent Nerves
}

\author{
(D) Hirosato Kanda, ${ }^{1,2}$ Sotatsu Tonomura, ${ }^{1}$ and Jianguo G. Gu ${ }^{1}$
}

https://doi.org/10.1523/ENEURO.0308-21.2021

${ }^{1}$ Department of Anesthesiology and Perioperative Medicine, School of Medicine, University of Alabama at Birmingham, Birmingham, AL 35294 and ${ }^{2}$ Department of Pharmacology, Hyogo University of Health Sciences, Kobe, Hyogo 650-8530, Japan

\begin{abstract}
Temperature-sensitive two-pore domain potassium channels (thermal K2P) are recently shown to cluster at nodes of Ranvier (NRs) and play a key role in action potential (AP) regeneration and conduction on $\mathrm{A} \beta$-afferent nerves. Cooling temperatures affect AP regeneration and conduction on $A \beta$-afferent nerves but the underlying mechanisms are not completely understood. Here, we have performed patch-clamp recordings directly at the NR in an ex vivo trigeminal nerve preparation. We have characterized the effects of cooling temperatures on intrinsic electrophysiological properties and AP regeneration at the NR on rat $\mathrm{A} \beta$-afferent nerves, and determined whether and how thermal K2P channels may be involved in the effects of cooling temperatures. We show that cooling temperatures from $35^{\circ} \mathrm{C}$ to $15^{\circ} \mathrm{C}$ decrease outward leak currents, increase input resistance, depolarize resting membrane potential (RMP), broaden AP width and increase latency of AP threshold at the NR. We further demonstrate that cooling temperatures impair regeneration of high-frequency AP trains at the NR. The effects of cooling temperatures on the intrinsic electrophysiological properties and regeneration of high-frequency AP trains at the NR can be partially reversed by $\mathrm{BL}-1249$ (BL), arachidonic acid (AA), and intra-axonal protons, three thermal K2P activators, indicating the involvement of thermal K2P channels. Moreover, we show that at cooling temperatures there are interplays among thermal K2P channels, RMPs, and voltage-gated $\mathrm{Na}^{+}$channels, which together limit regeneration of high-frequency AP trains at the NR. Our findings demonstrate a new role of thermal K2P channels in temperature-dependent conduction of high-frequency sensory signals.
\end{abstract}

Key words: $\mathrm{A} \beta$-afferent nerves; action potential; cooling temperature; node of Ranvier; saltatory conduction; two-pore domain $\mathrm{K}^{+}$channels

\section{Significance Statement}

Cooling temperatures impair high-frequency saltatory conduction along $\mathrm{A} \beta$-afferent nerves to compromise tactile acuity. Here, we have performed patch-clamp recordings directly at the node of Ranvier (NR) of rat trigeminal A $\beta$ afferent nerves to determine how cooling temperatures affect high-frequency saltatory conduction. We show that cooling temperatures via thermal K2P channels alter intrinsic electrophysiological properties and impair regeneration of high-frequency AP trains at the NR. Moreover, we demonstrate that there are interplays among thermal K2P channels, resting membrane potentials (RMPs) and voltage-gated $\mathrm{Na}^{+}$channels at cooling temperatures to limit regeneration of high-frequency action potential (AP) trains at the NR. Our findings establish a new role of thermal K2P channels in temperature-dependent conduction of somatosensory signals, which may have implications in cooling-induced sensory dysfunctions and analgesic effects of cooling. 


\section{Introduction}

Action potential (AP) propagation along myelinated nerves, known as saltatory (hop or leap in Latin) conduction, is achieved by APs leaping along myelinated nerves via the nodes of Ranvier (NRs; Ranvier, 1871, 1872; Lillie, 1925; Tasaki, 1939; Huxley and Stampfli, 1949; Boullerne, 2016). Saltatory conduction can reach speeds over $100 \mathrm{~m} / \mathrm{s}$ and frequencies over hundreds of hertz. In somatosensory nerves, saltatory conduction along $\mathrm{A} \beta$-afferent nerves conveys sensory information essential for tactile tasks such as social interaction, environmental exploration, and tactile discrimination. High-speed conduction of APs along A $\beta$-afferent nerves ensures rapid sensory responses. On the other hand, high-frequency AP trains conducted along $\mathrm{A} \beta$-afferent nerves are essential for sensory acuity (Phillips and Matthews, 1993). Saltatory conduction can be profoundly affected by cooling temperatures. Most previous studies have focused on effects of cooling temperatures on AP conduction velocities (Franz and lggo, 1968; Cabanes et al., 2003; Stecker and Baylor, 2009). Cooling temperatures are also known to affect regeneration and conduction of high-frequency AP trains (Paintal, 1965; Franz and Iggo, 1968), but this effect has received less attention. Interestingly, it has been shown in humans that cooling temperatures can impair regeneration of high-frequency AP trains on afferent nerves leading to poor tactile discrimination (Phillips and Matthews, 1993).

Cooling temperatures can directly slow kinetics and reduce amplitudes of voltage-activated $\mathrm{Na}^{+}$currents (Matteson and Armstrong, 1982; Sarria et al., 2012). This is thought to be a major contributing factor by which cooling temperatures can impair regeneration of high-frequency AP trains on nerves including $\mathrm{A} \beta$-afferent fibers. In addition to directly affecting voltagegated $\mathrm{Na}^{+}$channels, cooling temperatures may suppress the activity of other ion channels to alter intrinsic electrophysiological properties of membranes at the NR. This may also be an important contributing factor causing impairment of regeneration of high-frequency AP trains on $\mathrm{A} \beta$-afferent fibers. However, this hypothesis has never been directly tested because of technical challenges in the application of patch-clamp recording technique aimed to study ion channels and their functions at the NR.

Received July 19, 2021; accepted August 17, 2021; First published August 27, 2021.

The authors declare no competing financial interests.

Author contributions: J.G.G. designed research; H.K. and S.T. performed research; H.K., S.T., and J.G.G. analyzed data; J.G.G. wrote the paper.

This work was supported by National Institutes of Health Grants NS109059, DE023090, and DE018661 (to J.G.G.).

Acknowledgements: We thank Dr. Jacques Wadiche for an earlier discussion on this study and Dr. Ryan Vaden for proofreading this manuscript.

Correspondence should be addressed to Jianguo G. Gu at jianguogu@ uabmc.edu.

https://doi.org/10.1523/ENEURO.0308-21.2021

Copyright @ 2021 Kanda et al.

This is an open-access article distributed under the terms of the Creative Commons Attribution 4.0 International license, which permits unrestricted use, distribution and reproduction in any medium provided that the original work is properly attributed.
Immunohistochemical studies have shown that voltage-gated $\mathrm{Na}^{+}$channels Nav1.6 and Nav1.2 are expressed at mammalian NRs (Caldwell et al., 2000; Waxman, 2006). Immunohistochemical studies also have shown that voltage-gated $\mathrm{K}^{+}$channels Kv7.2 (Devaux et al., 2004) and Kv3.1b (Devaux et al., 2003) are present at mammalian NRs, and $\mathrm{Kv} 1.1$ as well as Kv1.2 are present in juxtaparanodal regions of myelinated axons (Rhodes et al., 1997). Mechanisms underlying assembly of these ion channels and other proteins at the NR have been gradually understood (Rasband and Peles, 2021). Previous studies have failed to detect significant voltage-activated $\mathrm{K}^{+}$currents at intact NRs in myelinated nerves of mammals (Chiu and Ritchie, 1980), suggesting that voltagegated $\mathrm{K}^{+}$channels located at and near the NR are functionally silent. This raises the question of how APs can be repolarized to allow regeneration of APs at the NR. Only recently have we found that TREK-1 and TRAAK channels are clustered at the NR of rat myelinated nerves, functioning as principal $\mathrm{K}^{+}$channels for AP repolarization (Kanda et al., 2019). Another recent study also reports wide expression of TRAAK channels at the NR of myelinated nerves of mice (Brohawn et al., 2019).

TREK-1 and TRAAK belong to the two-pore domain $\mathrm{K}^{+}$ (K2P) channel family which mediate "leak" or "background" $\mathrm{K}^{+}$currents across cell membranes. K2P channels, distinct from voltage-gated $\mathrm{K}^{+}$channels (Goldstein et al., 2005; Lotshaw, 2007; Enyedi and Czirják, 2010; Viatchenko-Karpinski et al., 2018), are involved in setting resting membrane potentials (RMPs) and membrane input conductance (Enyedi and Czirják, 2010). K2P channels play roles in regulation of neuronal excitability, sensory transduction, and nociception (Lotshaw, 2007). Mutations of these channels result in abnormal functions of central and peripheral nervous systems in humans (Bauer et al., 2018; Royal et al., 2019). Interestingly, TREK-1 and TRAAK are highly temperature sensitive and can be substantially inhibited by cooling temperatures, and thus are termed thermal K2P channels (Maingret et al., 1999, 2000; Kim et al., 2001; Kang et al., 2005; Enyedi and Czirják, 2010; Viatchenko-Karpinski et al., 2018). TREK-1 and TRAAK clustered at NRs of $A \beta$-afferents play a key role in AP repolarization, and high-speed and high-frequency saltatory conduction (Kanda et al., 2019). Furthermore, TREK-1 and TRAAK channels are involved in cooling temperature-induced reduction of AP conduction velocities on $\mathrm{A} \beta$-afferent nerves (Kanda et al., 2019). Since cooling temperatures also affect regeneration and conduction of high-frequency AP trains (Paintal, 1965; Franz and Iggo, 1968), the aforementioned findings (Kanda et al., 2019) raise the question as whether and how thermal K2P channels may be involved in impairment of high-frequency AP trains on $\mathrm{A} \beta$-afferent nerves at cooling temperatures. In the present study, we set out to address this question by performing patch-clamp recordings directly at the NR of $A \beta$-afferent fibers in ex vivo preparations of rat trigeminal nerves. 


\section{Materials and Methods}

\section{Ex vivo trigeminal nerve preparation}

Adult Sprague Dawley rats (Envigo) of both sexes were used in this study. Unless otherwise indicated, animals included in the present study were at the ages of five to seven weeks. The rats were housed in a temperature-controlled animal facility $\left(23^{\circ} \mathrm{C}\right)$ and maintained on a $12 / 12 \mathrm{~h}$ light/dark cycle. Animal care and use conformed to $\mathrm{NIH}$ guidelines, and experimental protocols for animal use were approved (IACUC-21 486) by the Institutional Animal Care and Use Committee at the University of Alabama at Birmingham.

Rats were euthanized by overdose of isoflurane followed by decapitation, and trigeminal nerve bundles $(\sim 15$ $\mathrm{mm}$ ) with their ganglions were dissected out and placed in a Petri dish filled with ice cold Leibovitz's L-15 medium (Corning Cellgro). Under a dissection microscope, connective tissues on the surface of the nerve bundles were carefully removed with a pair of fine forceps. Trigeminal nerve bundles with their ganglions were then affixed in a recording chamber by a tissue anchor and submerged in a Krebs' solution that contained the following: $117 \mathrm{~mm}$ $\mathrm{NaCl}, 3.5 \mathrm{~mm} \mathrm{KCl}, 2.5 \mathrm{~mm} \mathrm{CaCl}_{2}, 1.2 \mathrm{~mm} \mathrm{MgCl}_{2}, 1.2 \mathrm{~mm}$ $\mathrm{NaH}_{2} \mathrm{PO}_{4}, 25 \mathrm{~mm} \mathrm{NaHCO}$, and $11 \mathrm{~mm}$ glucose. The Krebs' solution was saturated with $95 \% \mathrm{O}_{2}$ and $5 \% \mathrm{CO}_{2}$, had $\mathrm{pH}$ adjusted to 7.35 with $\mathrm{NaOH}$ and osmolarity adjusted to $324 \mathrm{mOsm}$ with sucrose, and maintained at room temperature of $24^{\circ} \mathrm{C}$. The recording chamber was mounted on the stage of an Olympus BX51 microscope equipped with IR-DIC and fluorescent imaging systems. To facilitate the penetration of patch-clamp electrodes through perineural tissues, the nerve bundles were briefly exposed to a mixture of $0.07 \%$ Dispase II (Roche) and $0.07 \%$ collagenase (MilliporeSigma) in Krebs' solution for $5 \mathrm{~min}$ at the room temperature, and the enzymes were then washed off with Krebs' solution. Unless otherwise indicated, the ex vivo trigeminal nerve preparation was continuously perfused with Krebs' bath solution at $24^{\circ} \mathrm{C}$.

\section{Pressure-clamped patch-clamp recordings at the NR}

NRs in myelinated nerves of ex vivo trigeminal nerve preparations were visualized under a $40 \times$ water immersion objective (NA 0.80) and with an infrared CCD camera (IR-1000, DAGE-MTI). Myelinated nerves chosen for all experiments had diameters (including myelin thickness) of $8-10 \mu \mathrm{m}$. These myelinated nerves were $\mathrm{A} \beta$-afferent nerve fibers based on conduction velocity (Kanda et al., 2019). Patch-clamp recordings were applied to the NR of trigeminal $A \beta$-afferent nerve fibers. In brief, recording electrodes were fabricated using a Flaming/ Brown Micropipette Puller (P-97, Shutter Instruments). The electrode resistance after filling recording electrode internal solutions were 8-10 $\mathrm{M} \Omega$. For all experiments, the recording electrode was filled with an internal solution containing the following: $105 \mathrm{~mm} \mathrm{~K}$-gluconate, 30 $\mathrm{mm} \mathrm{KCl,} 0.5 \mathrm{~mm} \mathrm{CaCl}_{2}$, $2.4 \mathrm{~mm} \mathrm{MgCl}_{2}, 5 \mathrm{~mm}$ EGTA, 10 mM HEPES, 5 mм Na $\mathrm{NTP}_{2}$, and 0.33 mм GTP-TRIS salt; the $\mathrm{pH}$ of the solution was adjusted to 7.35 with $\mathrm{KOH}$. The recording electrode was connected with a high- speed pressure-clamp device (HSPC-1; ALA Scientific Instruments) to control electrode internal pressure. A high positive pressure of $200 \mathrm{mmHg}$ was first applied via the recording electrode to pressure-clean the surface areas around the NR. Intraelectrode positive pressures were then reduced to $90 \pm 10 \mathrm{mmHg}$, while the recording electrode penetrated the perineurium wrapped on nodal axons. Once the recording electrode penetrated through the perineurium, intraelectrode pressure was reduced to $5 \mathrm{mmHg}$ to approach nodal axons. Optimally accessing nodal axon membranes was judged by the reduction of seal-test currents and the appearance of a small current oscillation. Once the electrode tip optimally assessed nodal membranes, intraelectrode positive pressure was gradually reduced and a pressure of $-6 \pm 2 \mathrm{mmHg}$ was applied into recording electrode until forming gigaohm seals (usually $>5 \mathrm{G} \Omega$ ) between the recording electrode and nodal axon membranes. To achieve whole-cell configuration, nodal membranes were ruptured by a train of short electrical pulses $( \pm 200 \mathrm{mV}, 20 \mathrm{~ms}$ each pulse) delivered through the patch-clamp recording electrode while intraelectrode pressure was held at a constant negative pressure of $-30 \mathrm{mmHg}$. After establishing whole-cell mode, negative pressure was reduced to $-5 \mathrm{mmHg}$ and maintained during recordings. Signals of voltage-clamp experiments were recorded and amplified using an Axopach 200B amplifier or a multiclamp 700B amplifier, filtered at $2 \mathrm{kHz}$ and sampled at $10 \mathrm{kHz}$ using the pCLAMP 10 software (Molecular Devices). Signals of current-clamp recordings for APs at the NR were low-pass filtered at $2 \mathrm{kHz}$ and sampled at $50 \mathrm{kHz}$.

To determine intrinsic electrophysiological properties including both passive and active properties of nodal membranes, patch-clamp recordings were performed under whole-cell current-clamp configuration. Step current pulses were injected into the NR through the recording electrode. Step currents ranged from -100 to $1800 \mathrm{pA}$ with increments of $50 \mathrm{pA}$ per step, and the duration of each step was $1 \mathrm{~s}$. Unless otherwise indicated, membrane potentials mentioned in texts have been corrected for the calculated junction potential of $12 \mathrm{mV}$.

To determine AP conduction at the NR of myelinated afferent nerves, APs were evoked at a peripheral end of the infraorbital nerve branch using a suction stimulation electrode. The suction stimulation electrode's tip size was $\sim 1$ $\mathrm{mm}$ in diameter and was fire-polished. The peripheral end of trigeminal afferent nerve (infraorbital branch) was aspirated into the suction stimulation electrode with a tight fitting by negative pressure. The negative pressure was continuously applied into the suction stimulation electrode to maintain the tight fitting during experiments. To initiate a train of APs at the peripheral end of the nerve, monophasic square wave pulses were generated by an electronic stimulator (Master-8, A.M.P.I.) and delivered via a stimulation isolator (ISO-Flex, A.M.P.I.) to the suction stimulation electrode. The duration of each stimulation pulse was $50 \mu \mathrm{s}$. Minimum stimulation intensity for evoking APs, i.e., stimulation threshold at the peripheral end of the nerves was first determined and then train stimulation was applied at the intensity of 2-fold threshold 
(3.52 $\pm 0.34 \mathrm{~mA}, n=12)$ throughout the experiments. To determine success rates of APs at the NR following different frequencies of train, stimulation pulses were applied to the trigeminal nerve bundles at frequencies of 1, 10, 50, $100,200,500$, and $1000 \mathrm{~Hz}$. Stimulation train duration was $20 \mathrm{~s}$, and intervals between stimulation trains were $30 \mathrm{~s}$. Success rates of APs regenerated at the NR were the percentage of successfully regenerated APs at the nodal recording sites during 20 -s train stimulation.

\section{AP-clamp recordings at the NR}

Pressure-clamped patch-clamp recordings were applied to the NR of $A \beta$-afferent nerves in ex vivo trigeminal nerves obtained from animals at the ages of 9-12 weeks. APs at the NR were first recorded under the current clamp configuration following electrical stimulation at peripheral ends of trigeminal nerve bundles. For AP-clamp experiments (Llinás et al., 1982; Liu et al., 2017), recordings were performed under the voltage-clamp configuration and each NR's own AP was used as the voltage command waveform. AP waveforms (AP train stimulations) were applied at frequencies of 10,50 , and $100 \mathrm{~Hz}$ for $20 \mathrm{~s}$. AP-clamp experiments were performed with nodal membranes held at -75 and $-84 \mathrm{mV}$, and experiments were performed at temperatures of $15^{\circ} \mathrm{C}$ and $35^{\circ} \mathrm{C}$. AP-evoked $\mathrm{Na}^{+}$currents were quantified by integrating net inward current during the rising phase of AP, starting at the baseline and continuing to the peak of AP wave forms.

\section{Effects of temperatures and K2P channel activators}

Effects of temperatures on intrinsic electrophysiological properties of nodal membranes as well as AP regeneration at the NR of trigeminal $A \beta$-afferent nerves were determined by the aforementioned electrophysiological experiments at Krebs' bath solution temperatures of $35^{\circ} \mathrm{C}, 24^{\circ} \mathrm{C}$, and $15^{\circ} \mathrm{C}$. The temperatures of bath solutions were controlled by a Peltier temperature control system (CL-200A, Warner Instrument), and were continuously monitored with a thermal probe placed in the recording chamber (TA-29, Warner Instrument). The bath solution was applied at $2 \mathrm{ml} / \mathrm{min}$ from a short tube $(500 \mu \mathrm{m}$ in internal diameter) whose outlet was positioned $1 \mathrm{~cm}$ away from the recording site. The time was $<1 \mathrm{~min}$ for warming from $24^{\circ} \mathrm{C}$ to $35^{\circ} \mathrm{C}$ and $<2$ min for cooling from $24^{\circ} \mathrm{C}$ to $15^{\circ} \mathrm{C}$ at the recording site.

Intrinsic electrophysiological properties of the NR were examined in the absence and presence of BL-1249 (BL; $10 \mu \mathrm{m}$, Tocris Bioscience), arachidonic acid (AA; $20 \mu \mathrm{m}$, Tocris Bioscience), or protons (intracellular low $\mathrm{pH}$ 5). These reagents were shown to potentiate leak $\mathrm{K}^{+}$channel activity at NRs (Kanda et al., 2019). These reagents were either applied through bath solution to the recording chambers $(\mathrm{BL})$ or applied intracellularly through recording electrode internal solutions (AA, protons). For pharmacology tests with bath application of BL, it was perfused to ex vivo nerve preparations for $10 \mathrm{~min}$ through a pinch valve drug delivery system (VC-6, Warner Instrument). For experiments with intracellular applications of testing compounds, each compound was dissolved in recording electrode internal solutions and recordings were performed 20 min after establishing whole-cell configuration.

\section{Data analysis}

Electrophysiological data were measured using Clampfit 10 (Molecular Devices). Data collected from trigeminal nerves of 16 male and 11 female animals were aggregated for data analysis since no significant differences in electrophysiological results were found between male and female animals. Outward Leak currents were measured at the membrane holding voltage of $-72 \mathrm{mV}$. Input resistance was determined with a $10-\mathrm{mV}$ voltage step from the membrane holding voltage of $-72 \mathrm{mV}$. RMPs were measured under current-clamp configuration at the zero holding current. AP rheobase was the threshold step current that evoked AP firing. AP threshold was the threshold potential at which AP upstroke started. Latency to AP was the time from the beginning of the step current to AP threshold. AP amplitude or upstroke was measured from AP threshold to AP peak. AP width was measured as the duration from $50 \%$ AP upstroke to $50 \%$ AP repolarization. All the above AP parameters were determined with the AP evoked by the rheobase step current at the NR. AP success rate at the NR was calculated as the number of APs recorded at the NR divided by the number of electrical stimuli, where the electrical stimuli were applied to the peripheral ends of trigeminal nerves at different frequencies for $20 \mathrm{~s}$. Curve-fitting was performed using a nonlinear regression fit with the following equation: $Y=100 /\left(1+10^{a}((\right.$ LoglC50-X)*HillSlope $\left.))\right)$, where $Y$ is normalized response (AP success rate), $X$ is variable (time or stimulation frequency), IC50 is time to $50 \%$ of success rate $\left(T_{50}\right)$ or stimulation frequency at which success rate is $50 \%$ $\left(\mathrm{FS}_{50}\right)$. All data analyses were performed using GraphPad Prism (version 7). Unless otherwise indicated, all data are reported as mean \pm SEM of $n$ independent observations. Statistical significance was evaluated using oneway ANOVA with Tukey's post hoc tests or Student's $t$ tests. Differences were considered to be significant with ${ }^{*} p<0.05,{ }^{\star *} p<0.01,{ }^{\star \star \star} p<0.001$, and not significant (ns) with $p \geq 0.05$.

\section{Results}

\section{Cooling temperatures alter intrinsic electrophysiological properties of the NR on A $\beta$ - afferent nerves}

We have hypothesized that cooling temperatures via thermal K2P channels alter intrinsic electrophysiological properties of the NR to affect regeneration of high-frequency AP trains on $\mathrm{A} \beta$-afferent fibers. To test this idea, we first determined effects of cooling temperatures on both passive and active membrane properties at the NR of $\mathrm{A} \beta$-afferent nerves in our ex vivo trigeminal nerve preparations by using the pressure-clamped patch-clamp recordings at the NR (Kanda et al., 2019, 2021). Figure $1 A$ illustrates a pressure-clamped patch-clamp recording experiment performed at an NR of a large diameter trigeminal afferent nerve. In this example, the axon was labeled intracellularly by the fluorescent dye Alexa Fluor 555 
A

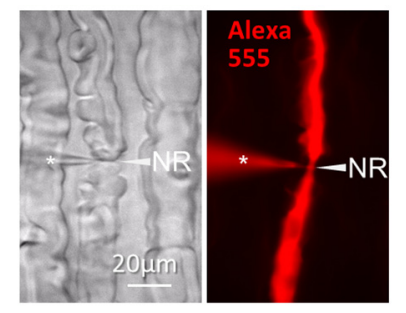

C

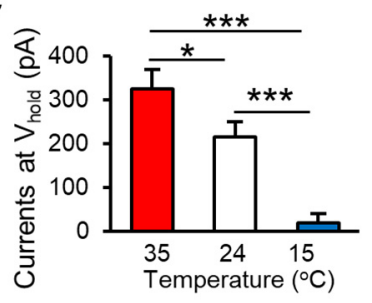

E

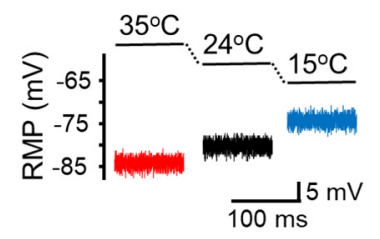

B

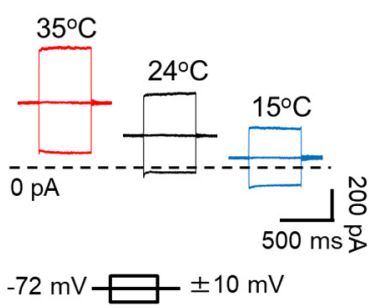

D

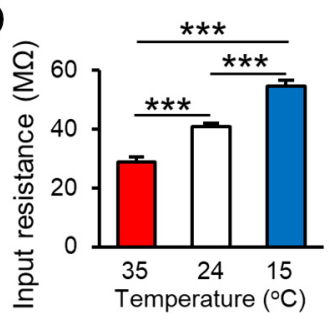

$\mathbf{F}$

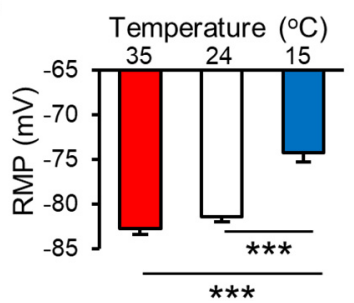

Figure 1. Cooling temperatures alter passive membrane properties of the NR on $A \beta$-afferent nerves. $\boldsymbol{A}$, left panel, bright field image shows $A \beta$-afferent nerves in an ex-vivo trigeminal afferent nerve preparation. Right panel, fluorescent image shows patch-clamp recordings at a NR of a trigeminal $A \beta$-afferent nerve. The electrode (asterisk indicated) contained Alexa Fluor 555 to trace the NR (arrow indicated) and other axonal regions. $\boldsymbol{B}$, Three sets of sample traces recorded at $35^{\circ} \mathrm{C}$ (left), $24^{\circ} \mathrm{C}$ (middle), and $15^{\circ} \mathrm{C}$ (right) show outward leak currents at the holding potential of $-72 \mathrm{mV}$ and membrane responses to \pm 10 $\mathrm{mV}$ voltage steps. Dashed line indicates the level of 0-pA current. $\boldsymbol{C}$, Summary data of the outward leak currents recorded at the NR at $35^{\circ} \mathrm{C}(n=8), 24^{\circ} \mathrm{C}(n=8)$, and $15^{\circ} \mathrm{C}(n=8)$. The outward leak currents were determined at the holding potential $\left(\mathrm{V}_{\text {hold }}\right)$ of $-72 \mathrm{mV}$. D , Summary data of the input resistance of nodal membranes determined at $35^{\circ} \mathrm{C}(n=11), 24^{\circ} \mathrm{C}(n=17)$, and $15^{\circ} \mathrm{C}(n=14)$. The input resistance was calculated based on the current following a $10-\mathrm{mV}$ voltage step. $\boldsymbol{E}$, Sample traces show nodal RMPs at $35^{\circ} \mathrm{C}, 24^{\circ} \mathrm{C}$, and $15^{\circ} \mathrm{C}$. $\boldsymbol{F}$, Summary data of the nodal RMP at $35^{\circ} \mathrm{C}(n=11), 24^{\circ} \mathrm{C}(n=17)$, and $15^{\circ} \mathrm{C}$ $(n=14)$. Data represent mean \pm SEM, ${ }^{*} p<0.05,{ }^{* *} p<0.01$, ${ }^{* *} p<0.001$, one-way ANOVA with the Tukey's post hoc test.

included in recording electrode internal solution (Fig. 1A). We performed recordings at NRs of myelinated trigeminal afferent nerves with outer diameters including myelin sheath $\sim 10 \mu \mathrm{m}$. We recently reported trigeminal afferent nerve fibers with diameters $\sim 10 \mu \mathrm{m}$ were $\mathrm{A} \beta$-afferent nerves based on conduction velocity (Kanda et al., 2019). In the present study, we found at NRs of $A \beta$-afferent nerves, membrane leak currents at the holding potential of $-72 \mathrm{mV}$ were outward, and progressively reduced with decreasing temperature from $35^{\circ} \mathrm{C}$ to $24^{\circ} \mathrm{C}$ and $15^{\circ} \mathrm{C}$ (Fig. $1 B)$. This is consistent with leak $\mathrm{K}^{+}$currents mediated by

the thermal K2P channels TREK-1 and TRAAK that are expressed at NRs of these afferent nerves as shown in our recent study (Kanda et al., 2019). The leak $\mathrm{K}^{+}$currents at holding potential of $-72 \mathrm{mV}$ were $324.9 \pm 44.1 \mathrm{pA}(n=8)$ at $35^{\circ} \mathrm{C}$, decreased to $216.1 \pm 34.7 \mathrm{pA}(n=8, p<0.05)$ at $24^{\circ} \mathrm{C}$, and further decreased to $18.9 \pm 20.1 \mathrm{pA}(n=8$, $p<0.001$ ) at the cooling temperature of $15^{\circ} \mathrm{C}$ (Fig. 1C). Reduction of leak $\mathrm{K}^{+}$currents was accompanied by increases of nodal membrane input resistance with cooling temperatures (Fig. 1D). Nodal membrane input resistances were obtained at the holding potential of $-72 \mathrm{mV}$ based on the membrane responses to $\pm 10 \mathrm{mV}$ membrane testing (Fig. 1B). The input resistance was $28.8 \pm 1.7 \mathrm{M} \Omega$ $(n=11)$ when measured at $35^{\circ} \mathrm{C}$ (Fig. $\left.1 B, D\right)$. As temperature was reduced, progressive increase in nodal membrane input resistance was observed. For example, nodal membrane input resistance was significantly increased to $40.8 \pm 1.1 \mathrm{M} \Omega(n=17, p<0.01)$ at $24^{\circ} \mathrm{C}$, and further increased to $54.5 \pm 2.1 \mathrm{M} \Omega(n=14, p<0.01)$ at $15^{\circ} \mathrm{C}$ (Fig. $1 D$ ). Importantly, accompanying reduced leak $\mathrm{K}^{+}$currents and increased nodal membrane input resistance, RMPs measured at NRs were progressively depolarized at cooling temperatures. At $35^{\circ} \mathrm{C}$, the RMP at NRs was at a hyperpolarized level of $-82.7 \pm 0.6 \mathrm{mV}(n=11$, Fig. $1 E, F)$, close to the reversal potentials of $\mathrm{K}^{+}$channels under our experimental conditions. The RMPs were significantly depolarized to $-74.2 \pm 1 \mathrm{mV}(n=14, p<0.001)$ at $15^{\circ} \mathrm{C}$ (Fig. $1 E, F)$. These results may suggest that cooling temperatures via inhibition of thermal K2P channels significantly shifted RMPs to depolarized levels at the NR.

We next determined effects of cooling temperatures on properties of APs at the NR. In this set of experiments, recordings were performed at the NR under whole-cell currentclamp configuration and APs were elicited by injecting step currents through the recording electrode (Fig. 2A). APs evoked by step currents at $35^{\circ} \mathrm{C}, 24^{\circ} \mathrm{C}$, and $15^{\circ} \mathrm{C}$ showed different kinetics as assessed by AP width (Fig. 2B,C). AP width was $0.52 \pm 0.03 \mathrm{~ms}(n=11)$ at $35^{\circ} \mathrm{C}$, and prolonged to $0.72 \pm 0.02 \mathrm{~ms}(n=17, p<0.001)$ at $24^{\circ} \mathrm{C}$, and further prolonged to $1.15 \pm 0.07 \mathrm{~ms}(n=14, p<0.001)$ at $15^{\circ} \mathrm{C} \mathrm{(Fig.} 2 \mathrm{C}$ ). Other significant changes in AP properties include amplitude (Fig. 2D), rheobase (Fig. 2E), and latency to AP threshold (Fig. 2G). AP amplitude or AP upstroke was $59.8 \pm 4.2 \mathrm{mV}(n=11)$ at $35^{\circ} \mathrm{C}$, and increased to $78.9 \pm 3.6 \mathrm{mV}(n=17, p<0.05)$ at $24^{\circ} \mathrm{C}$ and $77.3 \pm 4.3 \mathrm{mV}(n=14, p<0.001)$ at $15^{\circ} \mathrm{C}$ (Fig. $2 D$ ). AP rheobase was $881.8 \pm 60 \mathrm{pA}(n=11)$ at $35^{\circ} \mathrm{C}$, and decreased to $605.9 \pm 48.7 \mathrm{pA}(n=17, p<0.01)$ at $24^{\circ} \mathrm{C}$ and $471.4 \pm 32.6 \mathrm{pA}(n=11, p<0.001)$ at $15^{\circ} \mathrm{C}$ (Fig. 2E). AP threshold was $-38.9 \pm 1.9 \mathrm{mV}(n=11)$ at $35^{\circ} \mathrm{C}$, and was not significantly altered at $24^{\circ} \mathrm{C}$ and $15^{\circ} \mathrm{C}$ (Fig. 2F). At AP rheobase level, latency to AP threshold was $1.1 \pm 0.05 \mathrm{~ms}(n=7)$ at $35^{\circ} \mathrm{C}$, and significantly prolonged to $1.4 \pm 0.07 \mathrm{~ms}(n=7$, $p<0.05)$ at $24^{\circ} \mathrm{C}$ and $2.2 \pm 0.09 \mathrm{~ms}(n=7, p<0.001)$ at $15^{\circ} \mathrm{C}$ (Fig. 2G).

\section{Thermal K2P activators partially counteract cooling temperature-induced changes of intrinsic electrophysiological properties of the NR}

To support the idea that cooling temperature-induced changes of passive membrane properties at NRs were via 

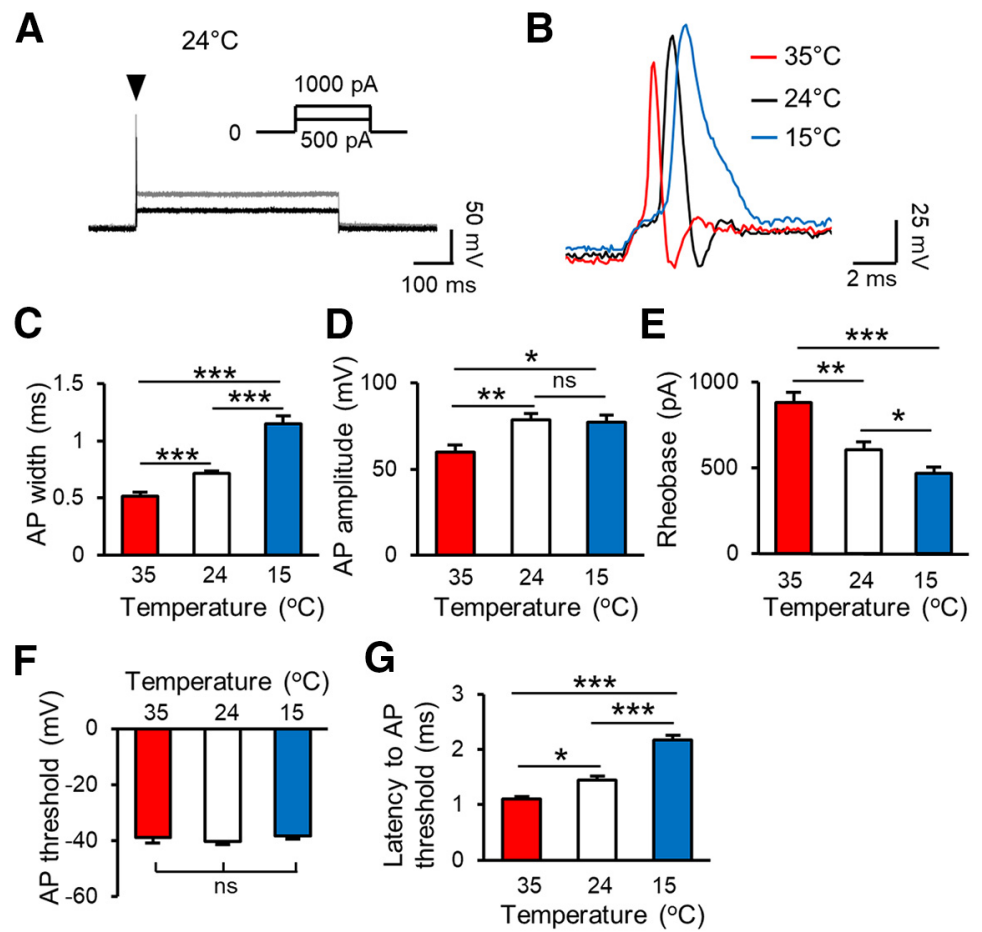

Figure 2. Cooling temperatures alter active membrane properties at the NR. A, Sample traces show APs (arrowhead indicated) recorded at a NR in response to step currents (inset) injected via recording electrode into the NR. The recording was performed under whole-cell current-clamp configuration at $24^{\circ} \mathrm{C}$. B. Three overlay sample traces at expanded scale show APs recorded at an NR at $35^{\circ} \mathrm{C}$ (red), $24^{\circ} \mathrm{C}$ (black), and $15^{\circ} \mathrm{C}$ (blue). APs were evoked by rheobase step currents injected through recording electrode into the NR. C-G, Summary data at $35^{\circ} \mathrm{C}(n=11), 24^{\circ} \mathrm{C}(n=17)$, and $15^{\circ} \mathrm{C}(n=14)$ of AP width $(\boldsymbol{C})$, amplitude or upstroke $(\boldsymbol{D})$, rheobase $(\boldsymbol{E})$, threshold $(\boldsymbol{F})$, and latency to AP threshold $(\boldsymbol{G})$. Data represent mean \pm SEM, ${ }^{\star} p<0.05$, ${ }^{* *} p<0.01$, ${ }^{\star * *} p<0.001$, one-way ANOVA with the Tukey's post hoc test. ns, not significant.

suppressing thermal K2P channel activity, we investigated whether the effects of cooling temperatures could be reversed by thermal K2P activators. We have recently shown that the activity of thermal K2P channels at NRs can be potentiated by $\mathrm{BL}, \mathrm{AA}$, and intra-axon protons, three activators of thermal K2P channels (Enyedi and Czirják, 2010; Kanda et al., 2019). Therefore, we examined passive membrane properties at $15^{\circ} \mathrm{C}$ in the absence and presence of these activators. While cooling temperatures from $35^{\circ} \mathrm{C}$ to $15^{\circ} \mathrm{C}$ decreased leak $\mathrm{K}^{+}$current, increased input resistance and depolarized RMP at the NR (Fig. 1D-F), the effects of cooling temperatures were partially reversed by $B L, A A$, and protons (Fig. $3 A-$ $D$ ). For example, the leak $\mathrm{K}^{+}$current at holding potential of $-72 \mathrm{mV}$ was $34.3 \pm 23 \mathrm{pA}(n=7)$ at $15^{\circ} \mathrm{C}$ in the absence of thermal $\mathrm{K} 2 \mathrm{P}$ activators, and increased to $99.3 \pm 34.6 \mathrm{pA}(n=7, p<0.05)$ in the presence of $10 \mu \mathrm{M}$ BL, $131.1 \pm 26.4 \mathrm{pA}(n=9, p<0.01)$ in the presence of $20 \mu \mathrm{M} \mathrm{AA}$, and 106.3 $\pm 43.9 \mathrm{pA}(n=8, p<0.05)$ in the presence of protons $\left([\mathrm{pH}]_{\mathrm{i}}=5\right.$; Fig. $\left.3 B\right)$. The input resistance was $54.2 \pm 2.5 \mathrm{M} \Omega(n=6)$ at $15^{\circ} \mathrm{C}$ in the absence of thermal K2P activators, and decreased to $43.3 \pm 1.7 \mathrm{M} \Omega$ $(n=9, p<0.01)$ in the presence of $10 \mu \mathrm{M} \mathrm{BL}, 45.9 \pm 1.7$ $\mathrm{M} \Omega(n=8, p<0.05)$ in the presence of $20 \mu \mathrm{M} \mathrm{AA}$, and $46.3 \pm 3.8 \mathrm{M} \Omega(n=8, p<0.05)$ in the presence of protons $\left([\mathrm{pH}]_{\mathrm{i}}=5\right.$, Fig. $\left.3 C\right)$. The RMP was $-73.0 \pm 1.6 \mathrm{mV}(n=6)$ at $15^{\circ} \mathrm{C}$ in the absence of thermal K2P activators, and became more negative at $-77.9 \pm 0.9 \mathrm{mV}(n=7, p<$ $0.05)$ in the presence of $10 \mu \mathrm{M} \mathrm{BL},-78.3 \pm 0.9 \mathrm{mV}(n=9$, $p<0.05)$ in the presence of $20 \mu \mathrm{M} \mathrm{AA}$, and $-78.3 \pm 1.9$ $\mathrm{mV}(n=8, p<0.05)$ in the presence of protons $\left([\mathrm{pH}]_{\mathrm{i}}=5\right.$, Fig. $3 D, E)$. These results suggest that thermal K2P channels are involved in cooling temperature-induced changes of the passive membrane properties at the NR.

To determine whether effects of cooling temperatures on active membrane properties at NRs were also mediated by thermal K2P channels, we tested effects of thermal K2P activators on AP properties at NRs at cooling temperatures. While cooling temperature of $15^{\circ} \mathrm{C}$ significantly prolonged AP width (Fig. $2 \mathrm{C}$ ), AP width at $15^{\circ} \mathrm{C}$ was shortened significantly in the presence of $\mathrm{BL}, \mathrm{AA}$, or protons (Fig. $4 B$ ). For example, AP width was $1.18 \pm 0.02 \mathrm{~ms}(n=6)$ at $15^{\circ} \mathrm{C}$ in the absence of thermal K2P activators, and shortened to $0.84 \pm 0.02 \mathrm{~ms}(n=8, p<0.01)$ in the presence of 10 $\mu \mathrm{M} \mathrm{BL}, 0.91 \pm 0.03 \mathrm{~ms}(n=7, p<0.01)$ in the presence of $20 \mu \mathrm{M} \mathrm{AA}$, and $0.9 \pm 0.03 \mathrm{~ms}(n=8, p<0.01)$ in the presence of protons $\left([\mathrm{pH}]_{i}=5\right.$; Fig. $\left.4 B\right)$. AP amplitude, threshold, and rheobase were not significantly affected by these K2P activators (Fig. 4C-E). At the rheobase level, latency to AP threshold was significantly shortened by the K2P activators (Fig. 4F). The latency was $2.4 \pm 0.2 \mathrm{~ms}(n=6)$ at $15^{\circ} \mathrm{C}$ in the absence 


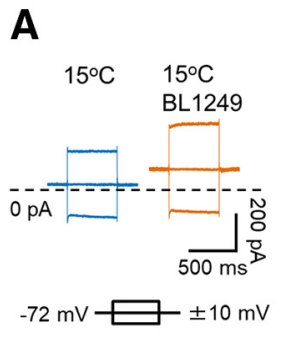

B

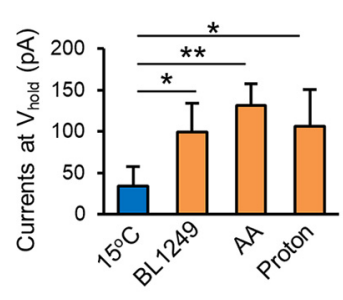

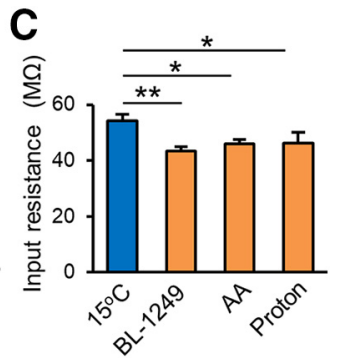
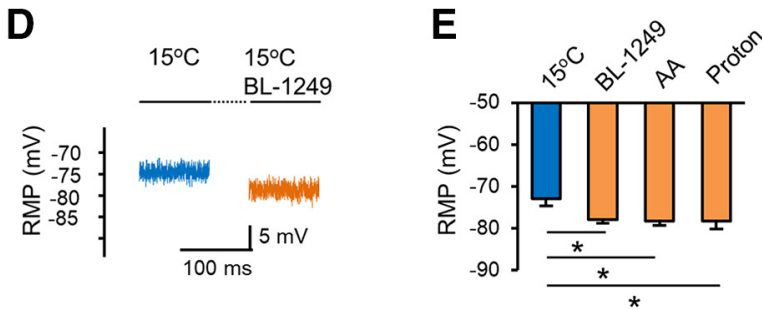

Figure 3. Thermal K2P activators partially counteract cooling temperature-induced changes of passive membrane properties of the NR. $\boldsymbol{A}$, Two sets of sample traces show outward leak currents and membrane responses to testing pulses of \pm 10 -mV voltage steps at cooling temperature of $15^{\circ} \mathrm{C}$ in the absence (left) and presence the thermal K2P activator BL (right). Nodal membranes were held at $-72 \mathrm{mV}$. Dashed line indicates the level of 0-pA current. $\boldsymbol{B}$, Summary data of outward leak currents determined at the $\mathrm{NR}$ at $15^{\circ} \mathrm{C}$ in the absence $(n=6)$, presence of thermal K2P activators BL $(10 \mu \mathrm{M}, n=9)$, AA $(20 \mu \mathrm{M}, n=8)$, and protons $\left([\mathrm{pH}]_{\mathrm{i}}=5, n=8\right)$. Nodal membranes were held at $-72 \mathrm{mV}$. C. Summary date of nodal membrane input resistance at $15^{\circ} \mathrm{C}$ in the absence $(n=6)$, presence of $10 \mu \mathrm{M} \mathrm{BL}$ $(n=9), 20 \mu \mathrm{M} \mathrm{AA}(n=8)$, and protons $\left([\mathrm{pH}]_{\mathrm{i}}=5, n=8\right)$. $\boldsymbol{D}$. Sample traces show RMPs at the NR at $15^{\circ} \mathrm{C}$ in the absence $(\mathrm{Blue})$ and presence of $10 \mu \mathrm{M} \mathrm{BL}$ (orange). $\boldsymbol{E}$, Summary data of RMP at $15^{\circ} \mathrm{C}$ in the absence $(n=6)$, presence of $10 \mu \mathrm{M} \mathrm{BL}(n=7), 20 \mu \mathrm{M} \mathrm{AA}(n=9)$, and protons $\left([\mathrm{pH}]_{\mathrm{i}}=5, n=8\right)$. In all experiments, $\mathrm{BL}$ was bath applied, $\mathrm{AA}$ and protons $\left([\mathrm{pH}]_{\mathrm{i}}=5\right.$ ) were applied intracellularly through recording electrode internal solution. Data represent mean \pm SEM, ${ }^{*} p<0.05,{ }^{* *} p<0.01$, one-way ANOVA with the Tukey's post hoc test.

of thermal K2P activators, and shortened to $1.78 \pm 0.12 \mathrm{~ms}$ $(n=8, p<0.05)$ in the presence of $10 \mu \mathrm{M} B \mathrm{BL}, 1.75 \pm$ $0.17 \mathrm{~ms}(n=6, p<0.05)$ in the presence of $20 \mu \mathrm{MAA}$, and $1.87 \pm 0.1 \mathrm{~ms}(n=6, p<0.05)$ in the presence of protons $\left([\mathrm{pH}]_{\mathrm{i}}=5\right.$; Fig. $\left.4 F\right)$. These results suggest that thermal K2P channels are involved in cooling temperature-induced changes of some active membrane properties at the NR.

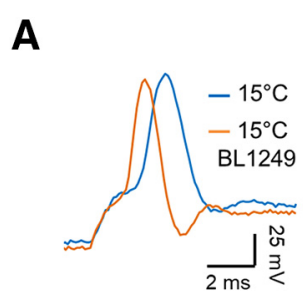

D

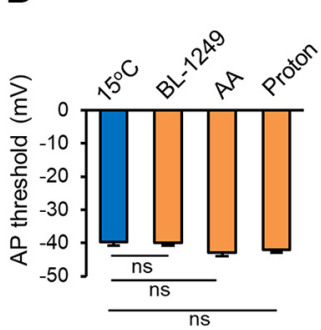

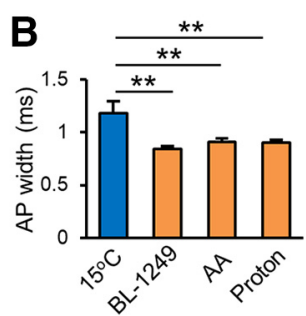

E

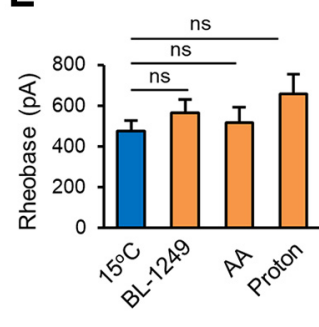

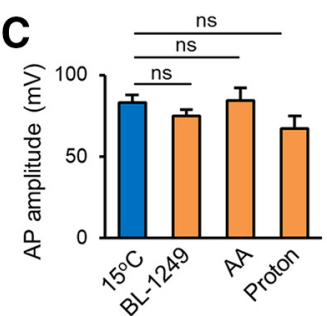

$\mathbf{F}$

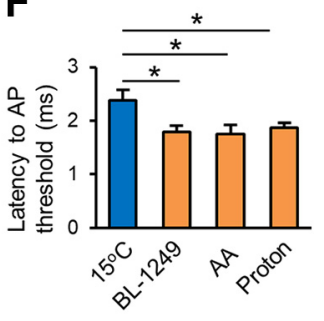

Figure 4. Effects of thermal K2P activators on active membrane properties at the NR at cooling temperatures. $\boldsymbol{A}$, Two overlay sample traces of APs recorded at a NR at cooling temperature of $15^{\circ} \mathrm{C}$ in the absence (blue) and presence of $10 \mu \mathrm{M} B \mathrm{~L}$ (orange). APs were evoked by rheobase step currents injected through recording electrode into the NR. $\boldsymbol{B}-\boldsymbol{F}$, Summary data of active membrane properties at $15^{\circ} \mathrm{C}$ in the absence $(n=6)$, present of $10 \mu \mathrm{M} \mathrm{BL}(n=8), 20 \mu \mathrm{M} \mathrm{AA}(n=7)$, and protons $\left([\mathrm{pH}]_{\mathrm{i}}=5, n=8\right)$. Active membrane properties measured at the NR include AP width $(\boldsymbol{B})$, amplitude $(\boldsymbol{C})$, threshold $(\boldsymbol{D})$, rheobase $(\boldsymbol{E})$, and latency to AP threshold $(\boldsymbol{F})$. Data represent mean $\pm \mathrm{SEM}$; ns, not significantly different, ${ }^{\star} p<0.05,{ }^{* *} p<0.01$, one-way ANOVA with the Tukey's post hoc test. 
A

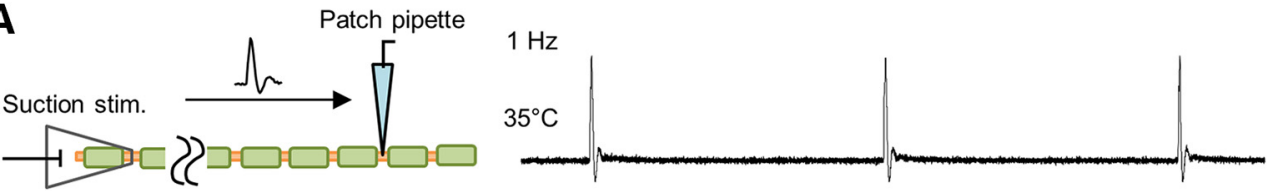

B
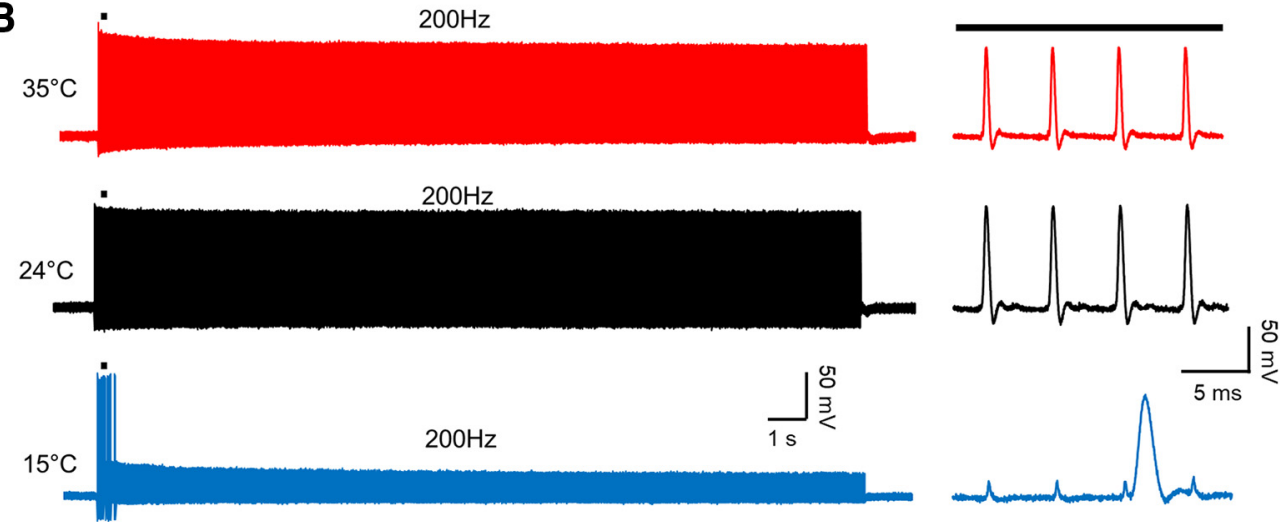

C

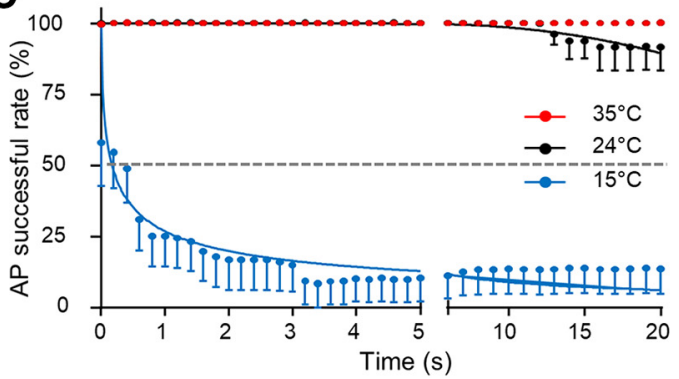

D

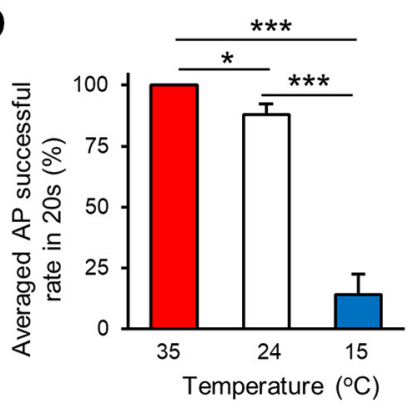

Figure 5. Cooling temperatures reduce AP success rate at the NR in response to $200-\mathrm{Hz}$ train stimulation. $\boldsymbol{A}$, Schematic diagram illustrates experimental setting (left) and sample traces of APs evoked by electrical stimulation and recorded at a NR at $35^{\circ} \mathrm{C}$ (right). Electrical stimulation was applied at $1 \mathrm{~Hz}$ at a distal site of the nerve bundle. $\boldsymbol{B}$, Three sets of sample traces show APs recorded at $35^{\circ} \mathrm{C}$ (top), $24^{\circ} \mathrm{C}$ (middle), and $15^{\circ} \mathrm{C}$ (bottom) in response to $200-\mathrm{Hz}$ train stimulation for $20 \mathrm{~s}$. Traces on right are at expanded scale. $\boldsymbol{C}$, Time course of AP success rates in response to $200-\mathrm{Hz}$ train stimulation for $20 \mathrm{~s}$ with experiments conducted at $35^{\circ} \mathrm{C}$ (red circles, $n=6$ ), $24^{\circ} \mathrm{C}$ (black circles, $n=6$ ), and $15^{\circ} \mathrm{C}$ (blue circles, $n=6$ ). Time bin: $200 \mathrm{~ms}$. $\boldsymbol{D}$, Bar graph shows averaged AP success rate at $35^{\circ} \mathrm{C}(n=6), 24^{\circ} \mathrm{C}(n=6)$, and $15^{\circ} \mathrm{C}(n=6)$ in response to the $200-\mathrm{Hz}$ train stimulation for $20 \mathrm{~s}$. Data represent mean $\pm \mathrm{SEM}$, ${ }^{\star} p<0.05,{ }^{* \star *} p<0.001$, one-way ANOVA with the Tukey's post hoc test.

\section{Cooling temperatures suppress and thermal K2P activators partially rescue the regeneration of high- frequency AP trains at the NR}

We have previously shown that APs can be regenerated at the NR with high success rates at $24^{\circ} \mathrm{C}$ in response to train stimulation at frequencies up to $200 \mathrm{~Hz}$. (Kanda et al., 2019). In the present study, we investigated effects of cooling temperatures on success rates of AP regeneration at the NRs, and the involvement of thermal K2P channels in changes of AP success rate. In this set of experiments, APs were elicited by train stimulation applied to a distal end of the nerve bundle, and APs were recorded at a NR that was $\sim 15 \mathrm{~mm}$ away from the stimulation site (Fig. $5 A$ ). As shown in Figure $5 B-D$, at $35^{\circ} \mathrm{C}, \mathrm{A} \beta$-afferent fibers followed $200-\mathrm{Hz}$ train stimulation with AP success rate near $100 \%$ during the course of $20-\mathrm{s}$ train stimulation. At $24^{\circ} \mathrm{C}$, AP success rate remained nearly $100 \%$ for up to $12 \mathrm{~s}$ and slightly decreased in the remaining $8 \mathrm{~s}$ of $200-\mathrm{Hz}$ train stimulation (Fig. 5B,C). In contrast, at the cooling temperature of $15^{\circ} \mathrm{C}$ and with $200-\mathrm{Hz}$ train stimulation, AP success rate rapidly dropped to $<25 \%$ in $<2$ s (Fig. $5 B, C)$. The APs mostly failed to regenerate in the remaining time of the 20 -s train stimulation at $15^{\circ} \mathrm{C}$ (Fig. $5 \mathrm{C}$ ). On average for the train stimulation at $200 \mathrm{~Hz}$ for $20 \mathrm{~s}$, AP success rate was $100 \pm 0 \%(n=6)$ at $35^{\circ} \mathrm{C}$, slightly reduced to $88 \pm 4.3 \%(n=6, p<0.05)$ at $24^{\circ} \mathrm{C}$, and largely reduced to $14 \pm 8.6 \%(n=6, p<0.001)$ at the cooling temperature of $15^{\circ} \mathrm{C}$ (Fig. $5 D$ ).

To test the idea that thermal Kv2P channels at NRs are involved in the reduction of AP success rates at cooling temperatures, we investigated whether thermal K2P activators could reverse the effects of cooling temperatures on AP success rate. In this set of experiments, APs elicited with $200-\mathrm{Hz}$ train stimulation for $20 \mathrm{~s}$ were recorded at $\mathrm{NRs}$ at $15^{\circ} \mathrm{C}$ in the absence, or presence of $\mathrm{BL}, \mathrm{AA}$ or protons. As shown in Figure $6 A, B$, AP success rate in response to $200-\mathrm{Hz}$ train stimulation rapidly decreased over time at $15^{\circ} \mathrm{C}$ in the absence of thermal K2P activators 


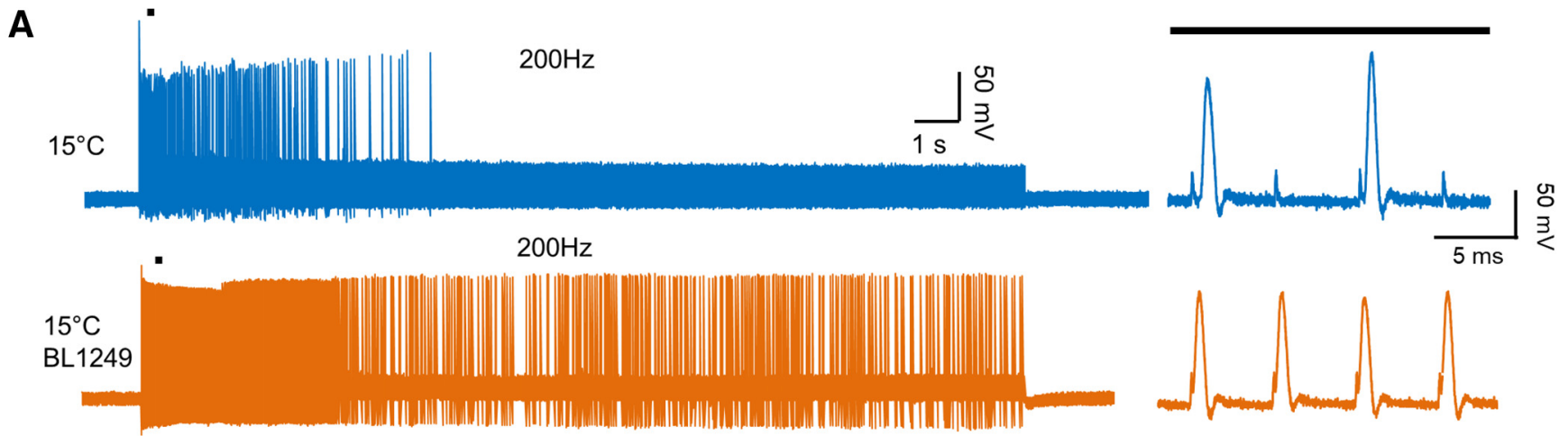

B
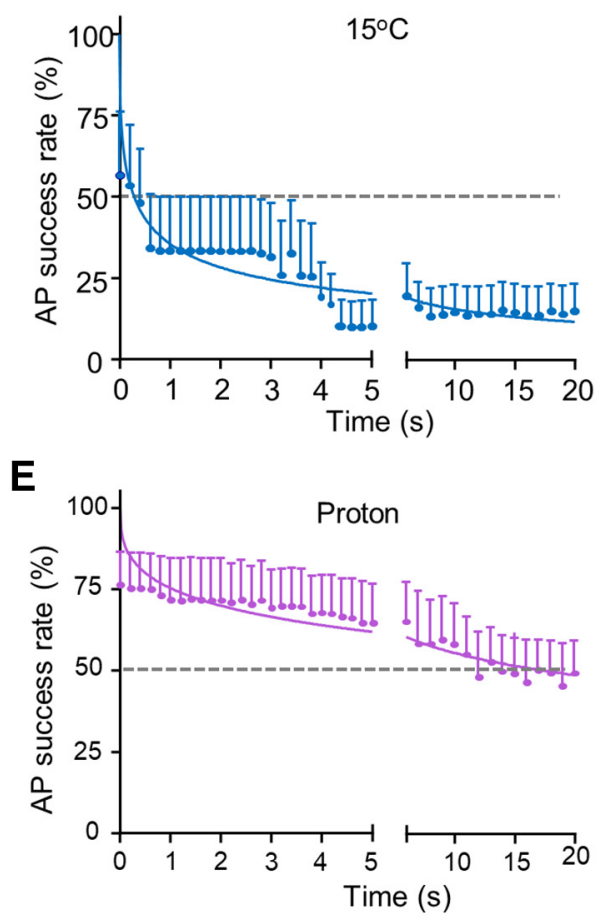

C

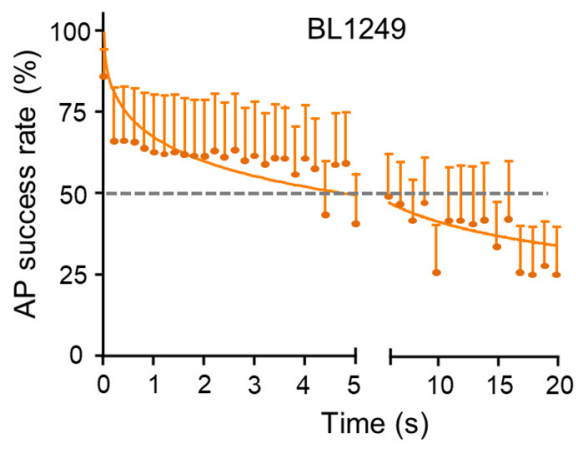

F

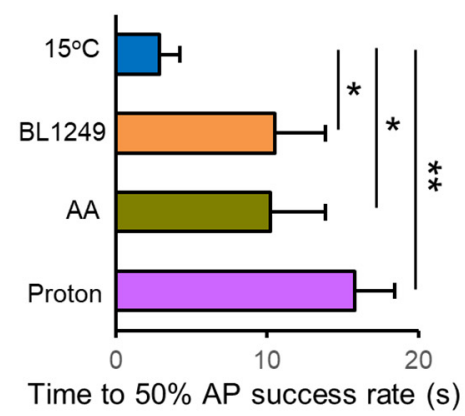

D

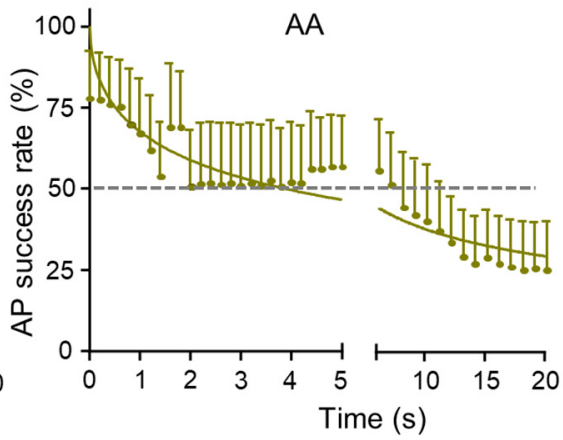

G

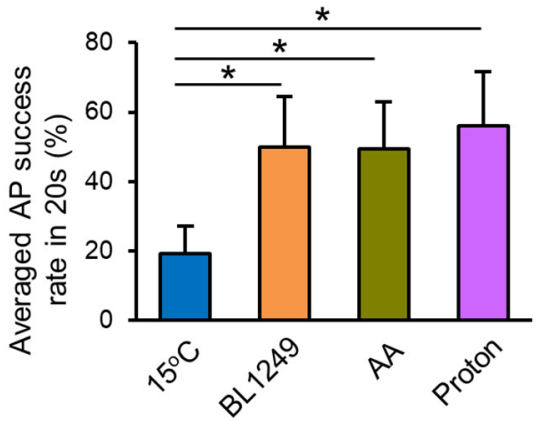

Figure 6. Thermal K2P activators partially counteract cooling temperature-induced reduction of AP success rate in response to $200-\mathrm{Hz}$ train stimulation. $\boldsymbol{A}$, Two sets of sample traces show nodal APs evoked by $200-\mathrm{Hz}$ train stimulation for $20 \mathrm{~s}$ in the absence (top), and presence (bottom) of $10 \mu \mathrm{M} \mathrm{BL}$. Experiments were performed at $15^{\circ} \mathrm{C}$. Traces on the right are at an expanded scale. $\boldsymbol{B}-\boldsymbol{E}$, Time course of success rate of nodal APs over $20 \mathrm{~s}$ in the absence $(\boldsymbol{B}, n=6)$, presence of $10 \mu \mathrm{M} \mathrm{BL}(\boldsymbol{C}, n=6), 20 \mu \mathrm{m} \mathrm{AA}(\boldsymbol{D}, n=6)$, or protons $\left(\boldsymbol{E},[\mathrm{pH}]_{\mathrm{i}}=5, n=6\right)$. Time bin: $200 \mathrm{~ms}$. Dashed line in each panel indicates $50 \%$ AP success rate. $\boldsymbol{F}$, Summary data of the time at which nodal AP success rate at $15^{\circ} \mathrm{C}$ reduced to $50 \%\left(\mathrm{~T}_{50}\right)$ in the absence (control, $\left.n=6\right)$, present of $10 \mu \mathrm{M} \mathrm{BL}(n=6), 20 \mu \mathrm{M}$ AA $(n=6)$, and protons $\left([\mathrm{pH}]_{\mathrm{i}}=5, n=6\right)$. G, Summary data of averaged success rate of nodal APs in $20 \mathrm{~s}$ at $15^{\circ} \mathrm{C}$ in the absence (control, $n=6)$, presence of $10 \mu \mathrm{M} \mathrm{BL}(n=6), 20 \mu \mathrm{MAA}(n=6)$, and protons $\left([\mathrm{pH}]_{\mathrm{i}}=5, n=6\right)$. Data represent mean $\pm \mathrm{SEM},{ }^{*} p<0.05$, ${ }^{* *} p<0.01,{ }^{* \star *} p<0.001$, one-way ANOVA with the Tukey's post hoc test.

(Fig. $6 A, B)$. However, AP success rate was less reduced at $15^{\circ} \mathrm{C}$ in the presence of $10 \mu \mathrm{M} \mathrm{BL}$ (Fig. $6 A, C$ ), $20 \mu \mathrm{m} \mathrm{AA}$ (Fig. $6 D)$, or protons $\left([\mathrm{pH}]_{\mathrm{i}}=5\right.$; Fig. $\left.6 E\right)$. We used two parameters to quantitatively describe the effects of the thermal K2P activators on AP success rate following $200-\mathrm{Hz}$ train stimulation, the time at which AP success rate reduces to $50 \%\left(T_{50}\right.$; Fig. $\left.6 F\right)$ and average AP success rate during 20 -s train stimulation (Fig. $6 G$ ). At $15^{\circ} \mathrm{C}, \mathrm{T}_{50}$ was $2.87 \pm 1.38 \mathrm{~s}(n=6)$ in the absence of thermal K2P activators, and significantly prolonged to $10.5 \pm 3.33 \mathrm{~s}(n=6$, $p<0.05)$ in the presence of $10 \mu \mathrm{M} \mathrm{BL}, 10.2 \pm 3.6 \mathrm{~s}(n=6$, $p<0.05)$ in the presence of $20 \mu \mathrm{M} \mathrm{AA}$, and $15.7 \pm 2.68 \mathrm{~s}$ $(n=6, p<0.01)$ in the presence of protons $\left([\mathrm{pH}]_{\mathrm{i}}=5\right.$; Fig. $6 F)$. On average, AP success rate was $19.2 \pm 7.8 \%(n=6)$ in the absence of thermal K2P activators, and significantly increased to $49.9 \pm 14.5 \%(n=6, p<0.05)$ in the presence of $10 \mu \mathrm{M} \mathrm{BL}, 49.4 \pm 13.7 \%(n=6, p<0.05)$ in the presence of $20 \mu \mathrm{MAA}$, and $56 \pm 15.6 \%(n=5, p<0.05)$ in the presence of protons $\left([\mathrm{pH}]_{\mathrm{i}}=5\right.$; Fig. $\left.6 \mathrm{G}\right)$.

We extended the above experiments by testing effects of cooling temperatures and thermal K2P activators on AP success rate following a broad range of stimulation frequencies. In this set of experiments, APs were elicited at distal sites of afferent nerves by train stimulation for 

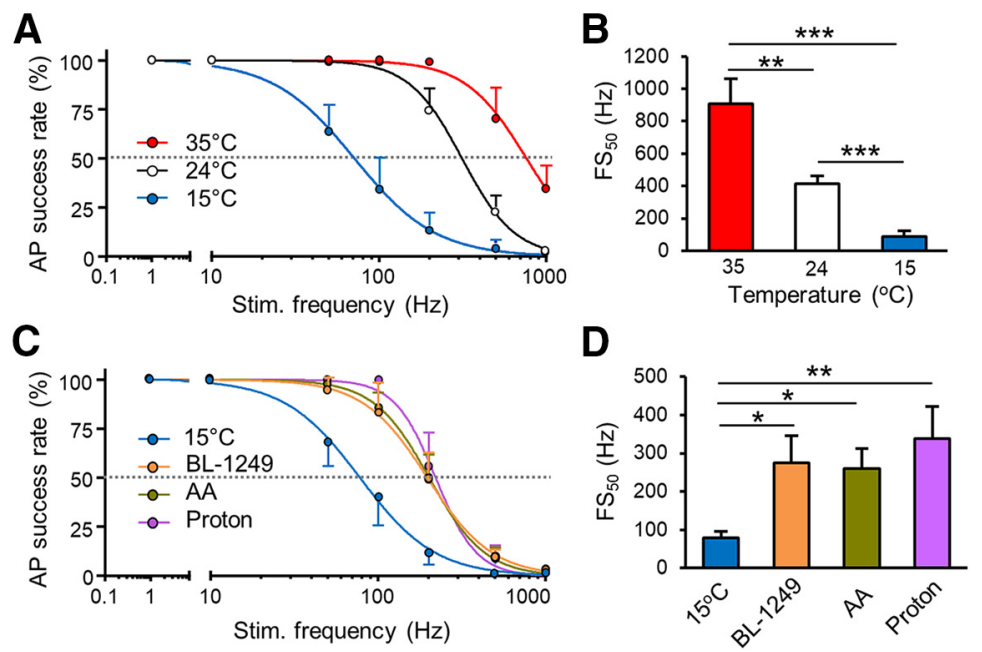

Figure 7. Temperature-dependent and frequency-dependent changes of AP success rate at the NR and effects of thermal K2P activators. $\boldsymbol{A}$, Plots of AP success rate against frequencies of train stimulation at $35^{\circ} \mathrm{C}(n=6), 24^{\circ} \mathrm{C}(n=6)$, and $15^{\circ} \mathrm{C}(n=6)$. Train stimulation was applied at frequencies of $1,10,50,100,200,500$, and $1000 \mathrm{~Hz}$ each for a duration of $20 \mathrm{~s}$. Dashed line indicates $50 \%$ AP success rate. $\boldsymbol{B}$, Bar graph shows summary data $(n=6)$ of $\mathrm{FS}_{50}$ values obtained from recordings performed at $35^{\circ} \mathrm{C}(n=6), 24^{\circ} \mathrm{C}$ $(n=6)$, and $15^{\circ} \mathrm{C}(n=6)$. FS 50 , frequencies at which the AP success rate is $50 \%$. C. Plots of AP success rate against different frequencies of train stimulation at $15^{\circ} \mathrm{C}$ in the absence $(n=6)$, presence of $10 \mu \mathrm{M} \mathrm{BL}(n=6), 20 \mu \mathrm{M}$ AA $(n=6)$, and protons $(n=5)$. Dashed line indicates $50 \%$ AP success rate. $\boldsymbol{D}$, Summary data of $\mathrm{FS}_{50}$ obtained from recordings at $15^{\circ} \mathrm{C}$ in the absence $(n=6)$, presence of $\mathrm{BL}(n=6), \mathrm{AA}(n=6)$, and protons $\left([\mathrm{pH}]_{\mathrm{i}}=5, n=5\right)$. Mean $\pm \mathrm{SEM},{ }^{\star} p<0.05,{ }^{* \star} p<0.01$, ${ }^{\star * *} p<0.001$, one-way ANOVA with the Tukey's post hoc test.

$20 \mathrm{~s}$ at frequencies of $1,10,50,100,200,500$, and $1000 \mathrm{~Hz}$. APs were recorded at NRs at three different temperatures, $35^{\circ} \mathrm{C}, 24^{\circ} \mathrm{C}$, and $15^{\circ} \mathrm{C}$. Figure $7 \mathrm{~A}$ shows temperature-dependent and frequency-dependent changes of AP success rate as recorded at the NR. At $35^{\circ} \mathrm{C}, \mathrm{AP}$ success rate was $100 \%$ for stimulation frequencies 1$200 \mathrm{~Hz}$, and reduced to $70.9 \pm 15.2 \%(n=6)$ at train stimulation frequency of $500 \mathrm{~Hz}$, and $35.1 \pm 11.6 \%(n=6)$ at train stimulation frequency of $1000 \mathrm{~Hz}$. At $24^{\circ} \mathrm{C}$, AP success rate versus stimulation frequency curve shifted to the left. AP success rate was $71.3 \pm 13 \%$ at train stimulation frequency of $200 \mathrm{~Hz}, 23.5 \pm 7.8 \%(n=6)$ at train stimulation frequency of $500 \mathrm{~Hz}$, and $0.97 \pm 0.4 \%(n=6)$ at train stimulation frequency of $1000 \mathrm{~Hz}$. At $15^{\circ} \mathrm{C}$, AP success rate versus train stimulation frequency curve further shifted left. AP success rate was $14 \pm 8.6 \%(n=6)$ at the train stimulation frequency of $200 \mathrm{~Hz}, 4.6 \pm 4.2 \%(n=6)$ at $500-\mathrm{Hz}$ train stimulation, and $0.2 \pm 0.2 \%(n=6)$ at $1000-\mathrm{Hz}$ train stimulation. We used the frequency at which AP success rate was $50 \%\left(\mathrm{FS}_{50}\right)$ to quantitatively describe the effects of temperatures and train stimulation frequency on AP success rates (Fig. $7 B$ ). $\mathrm{FS}_{50}$ was $910.1 \pm 154.4 \mathrm{~Hz}(n=6)$ at $35^{\circ} \mathrm{C}$, and significantly reduced to $414.9 \pm 51.9 \mathrm{~Hz}(n=6, p<0.01)$ at $24^{\circ} \mathrm{C}$, and $89.1 \pm 37.8 \mathrm{~Hz}(n=6, p<0.001)$ at $15^{\circ} \mathrm{C}$ (Fig. $7 B$ ). We further extended our study to quantitatively measure effects of thermal K2P activators on AP success rate at different stimulation frequencies at the cooling temperature of $15^{\circ} \mathrm{C}$. As shown in Figure $7 \mathrm{C}, \mathrm{AP}$ success rate versus train stimulation frequency curve at $15^{\circ} \mathrm{C}$ shifted to the right, i.e., higher frequency range, in the presence of $\mathrm{K} 2 \mathrm{P}$ activators $\mathrm{BL}$, $\mathrm{AA}$, or protons (Fig. $7 C$ ). Quantitatively measured with $\mathrm{FS}_{50}$, the $\mathrm{FS}_{50}$ was $78.3 \pm 16.4 \mathrm{~Hz}(n=8)$ in the absence of the K2P activators, and increased to $275.7 \pm 69.7 \mathrm{~Hz}(n=6, p<0.05)$ in the presence of $10 \mu \mathrm{M} \mathrm{BL}, 260.5 \pm 51.1 \mathrm{~Hz}(n=6, p<0.05)$ in the presence of $20 \mu \mathrm{M} \mathrm{AA}$, and $337.9 \pm 84.1 \mathrm{~Hz}(n=5$, $p<0.01)$ in the presence of protons $\left([\mathrm{pH}]_{\mathrm{i}}=5\right.$; Fig. $\left.7 D\right)$.

The above experiments with thermal K2P activators demonstrate the partial involvement of thermal K2P channels in cooling temperature-induced reduction of AP success rate. Strong non-inactivating outward currents in response to depolarizing voltage steps were recorded from the NRs and the outward currents were substantially suppressed at the cooling temperature of $15^{\circ} \mathrm{C}$ (Fig. 8A). We have previously characterized the outward currents at NRs at different temperatures, and shown these currents were mediated by the thermal K2P channels TREK- 1 and TRAAK and could be potentiated by $B L, A A$, or protons (Kanda et al., 2019). In addition to the non-inactivating outward currents (Fig. 8A), depolarizing voltage steps evoked transient inward currents (Fig. $8 A, B$ ) that were previously shown to be mediated by TTX-sensitive voltage-gated $\mathrm{Na}^{+}$channels (Kanda et al., 2019). The inward currents were large and fast, often resulting in current escape from voltage-clamp commands near activation threshold (Fig. 8B). However, the inward currents evoked at higher voltage such as at the step from -72 to $18 \mathrm{mV}$ showed no obvious escape from voltage-clamp as evidenced in the time course of the inward currents (Fig. 8B). Therefore, we chose the inward currents evoked by the step of $-72-18 \mathrm{mV}$ to quantitatively determine the effects of cooling temperatures on voltage-activated $\mathrm{Na}^{+}$current components at the NRs (Fig. $8 C, D$ ). It should be noted that our voltage-clamp commands for recording the voltage-activate $\mathrm{Na}^{+}$currents were approximate since it would be impossible to accurately voltage clamp the $\mathrm{Na}^{+}$ currents at the NR with a high resistance electrode. The 
A

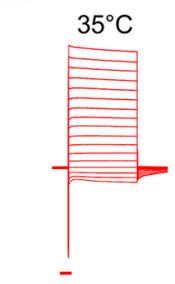

C
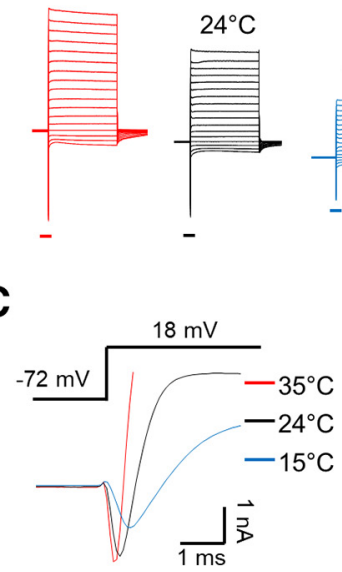

B
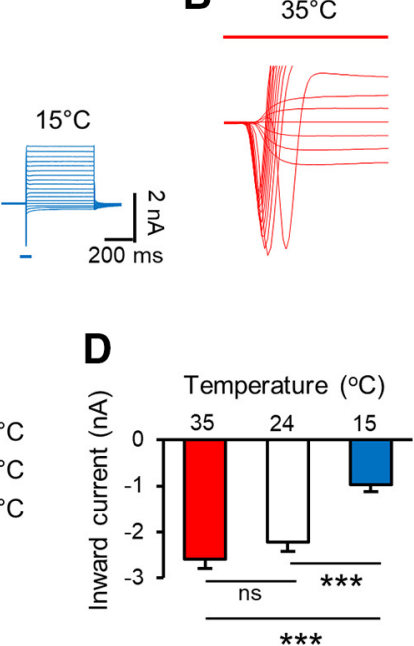

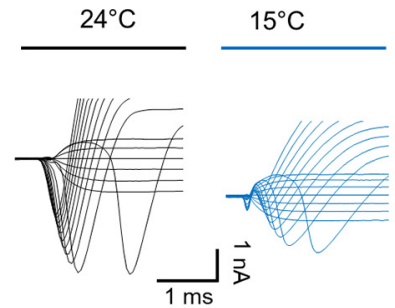

E

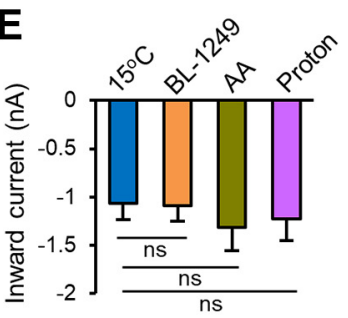

Figure 8. Effects of cooling temperatures and thermal K2P activators on voltage-gated $\mathrm{Na}^{+}$current components at the NR. $\boldsymbol{A}$, Three sets of sample traces show inward and outward currents following series of voltage steps; the recordings were performed at $35^{\circ} \mathrm{C}$ (right), $24^{\circ} \mathrm{C}$ (middle), and $15^{\circ} \mathrm{C}$ (left). Nodal membranes were held at $-72 \mathrm{mV}$. Voltage steps were applied from -102 to $58 \mathrm{mV}$ with a 10-mV increment each step. $\boldsymbol{B}$, Three sets of sample traces show inward current components at an expanded scale with the recordings performed at $35^{\circ} \mathrm{C}$ (left), $24^{\circ} \mathrm{C}$ (middle), and $15^{\circ} \mathrm{C}$ (right). $\boldsymbol{C}$, Three overlay sample traces of inward current components evoked by a voltage step from -72 to $18 \mathrm{mV}$; the recordings were performed at $35^{\circ} \mathrm{C}$ (red), $24^{\circ} \mathrm{C}$ (black), and $15^{\circ} \mathrm{C}$ (blue). $\boldsymbol{D}$, Summary data of the amplitudes of inward current components recorded at $35^{\circ} \mathrm{C}(n=8), 24^{\circ} \mathrm{C}(n=8)$, and $15^{\circ} \mathrm{C}(n=8)$. Voltage-step was from -72 to $18 \mathrm{mV}$. $\boldsymbol{E}$, Summary data of the amplitudes of inward current components recorded at $15^{\circ} \mathrm{C}$ in the absence $(n=6)$, presence of $10 \mu \mathrm{M} \mathrm{BL}(n=7), 20 \mu \mathrm{M} \mathrm{AA}(n=7)$, and protons ([pH5], $n=8)$. Voltage-step was from -72 to $18 \mathrm{mV}$. Data represent mean \pm SEM, ${ }^{*} p<0.05,{ }^{* \star} p<0.01,{ }^{\star \star *} p<0.001$, one-way ANOVA with the Tukey's post hoc test. ns, not significant.

amplitude of the inward current components was not significantly different between $35^{\circ} \mathrm{C}$ and $24^{\circ} \mathrm{C}$ (Fig. $8 \mathrm{C}, \mathrm{D}$ ). However, the inward current components measured at $15^{\circ} \mathrm{C}$ were significantly smaller in amplitudes and slower in kinetics than those measured at $35^{\circ} \mathrm{C}$ and $24^{\circ} \mathrm{C}$ (Fig. $8 D$ ). We next determined whether the inward current components at $15^{\circ} \mathrm{C}$ were affected by the thermal K2P activators. We found that the inward current components at $\mathrm{NRs}$ at $15^{\circ} \mathrm{C}$ were not significantly affected by $10 \mu \mathrm{M} \mathrm{BL}$ $(n=7), 20 \mu \mathrm{M}$ AA $(n=7)$, or protons $\left([\mathrm{pH}]_{i}=5, n=8\right)$. These results indicated that the effects of $B L, A A$, and protons on intrinsic electrophysiological properties and AP success rate were not because of potential non-specific effects on voltage-gated $\mathrm{Na}^{+}$channels at the NR. It should be noted that although voltage-gated $\mathrm{Na}^{+}$channels at the NR were significantly suppressed at the cooling temperature of $15^{\circ} \mathrm{C}$ (Fig. $8 D$ ), the AP amplitudes were significantly higher at $15^{\circ} \mathrm{C}$ than at $35^{\circ} \mathrm{C}$ (Fig. $\left.2 B, D\right)$.

\section{Cooling temperatures decrease availability of voltage- gated $\mathrm{Na}^{+}$channels at depolarized NRs to impair high-frequency AP train regeneration}

Cooling temperatures via thermal K2P channels caused substantial depolarization of RMPs at the NR (Figs. $1 F$, $3 E$ ). Depolarized NRs may promote steady-state inactivation of voltage-gated $\mathrm{Na}^{+}$channels at cooling temperatures (Zimmermann et al., 2007). This would reduce the availability of voltage-gated $\mathrm{Na}^{+}$channels for regeneration of high-frequency AP trains at the NR. To test this hypothesis, we applied AP-clamp recording technique (Liu et al., 2017) to the NR to investigate AP-activated $\mathrm{Na}^{+}$ currents in response to train stimulation with AP waveforms (AP train stimulation) at different frequencies (Fig. 9). In AP-clamp recordings, AP waveforms obtained from current-clamp recordings at the NR were applied as command voltages to the NR so that ionic currents during AP firing at the NR can be quantitatively determined. As exemplified in Figure $9 A$, application of AP waveforms to the NR evoked inward currents followed by outward currents. The inward currents were mediated by voltagegated $\mathrm{Na}^{+}$channels and outward currents by thermal K2P channels (Kanda et al., 2019). We performed APclamp recordings at $15^{\circ} \mathrm{C}$ with nodal membrane potentials held at $-75 \mathrm{mV}$ to determine how AP-activated $\mathrm{Na}^{+}$ currents were altered at different AP train stimulation frequencies (Fig. 9). The holding potential of $-75 \mathrm{mV}$ was selected in this set of experiments because it was approximately the RMP of the NR at $15^{\circ} \mathrm{C}$ (Fig. 1). As shown in Figure $9 A, B$, at $15^{\circ} \mathrm{C}$ and $-75-\mathrm{mV}$ holding potential, the inward currents were $1.493 \pm 0.126 \mathrm{nA}(n=9)$ at initial time point $(0 \mathrm{~s})$ and remained unchanged to the end of 10$\mathrm{Hz}$ AP train stimulation. However, with $50-\mathrm{Hz}$ AP train stimulation, inward current amplitudes rapidly reduced by $\sim 50 \%$ and stayed reduced in the remaining AP train stimulation (Fig. 9A,B). Furthermore, with 100-Hz AP train stimulation, the inward current rapidly reduced becoming nearly negligible in the remaining $100-\mathrm{Hz}$ AP train stimulation (Fig. 9A,B).

We next performed $\mathrm{AP}$-clamp recordings at the $\mathrm{NR}$ at a holding potential of $-84 \mathrm{mV}$ to determine how a hyperpolarized membrane potential may affect AP-activated $\mathrm{Na}^{+}$ currents at $15^{\circ} \mathrm{C}$. As shown in Figure $9 C, D$, inward currents were $2.175 \pm 0.207 \mathrm{nA}(n=9)$ at initial time point $(0 \mathrm{~s})$ 
A

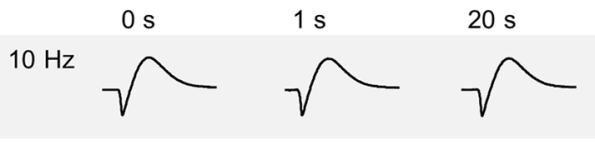

$50 \mathrm{~Hz}$

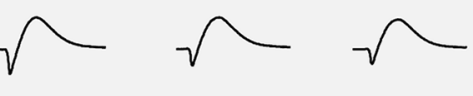

$100 \mathrm{~Hz}$
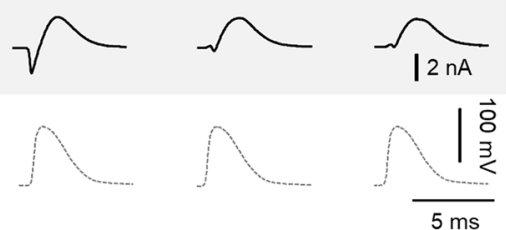

C

$10 \mathrm{~Hz}$

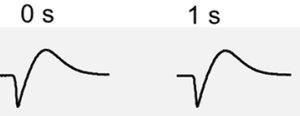

$50 \mathrm{~Hz}$
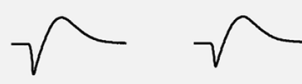

$100 \mathrm{~Hz}$
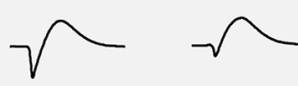

$-84 \mathrm{mV}$

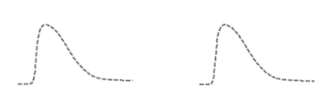

E

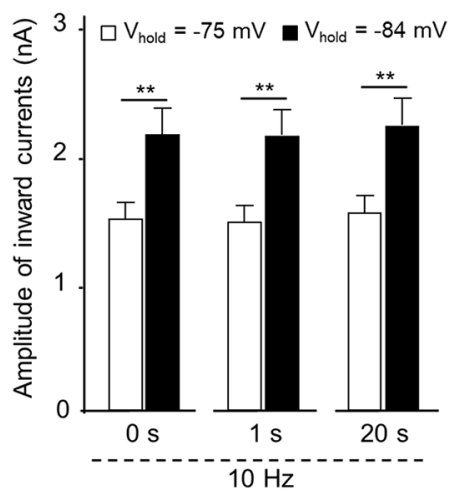

B

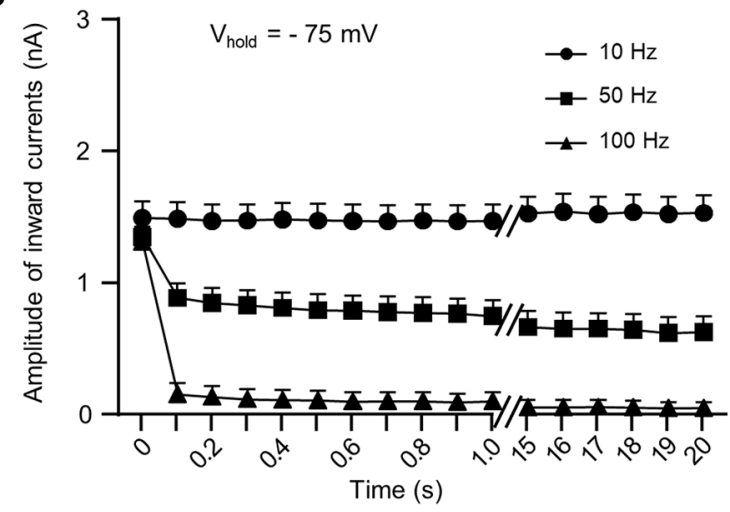

$20 \mathrm{~s} \quad$ D

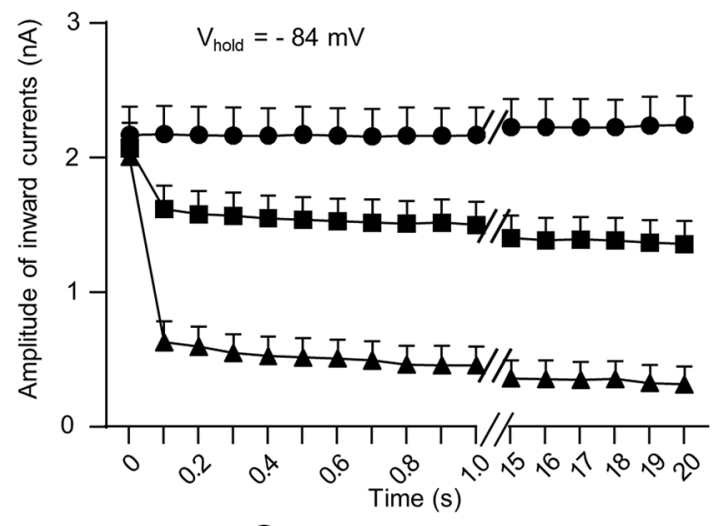

G
$\mathbf{F}$

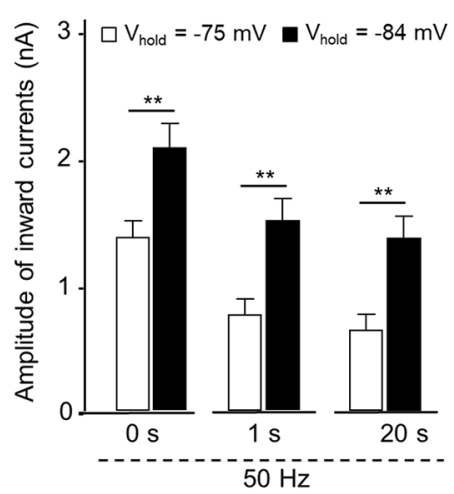

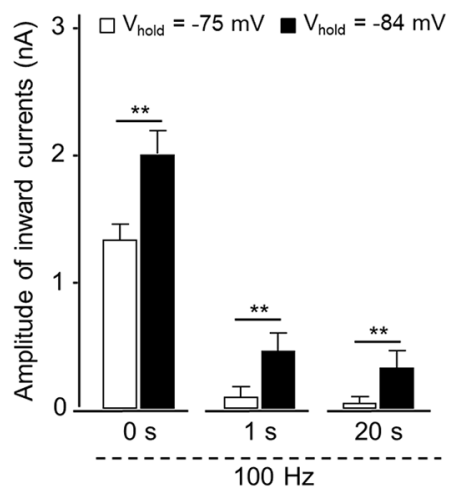

Figure 9. Membrane potential-dependent and frequency-dependent alterations of AP-activated $\mathrm{Na}^{+}$currents at the $\mathrm{NR}$ at $15^{\circ} \mathrm{C}$. $\boldsymbol{A}$, Three sets of sample traces of nodal membrane currents evoked by AP train stimulation at $10 \mathrm{~Hz}$ (first row), $50 \mathrm{~Hz}$ (second row), and $100 \mathrm{~Hz}$ (third row). Nodal membrane potentials were held at $-75 \mathrm{mV}$ and experiments performed at cooling temperature of $15^{\circ} \mathrm{C}$. In each row, sample traces on left, middle, and right are the currents evoked at time points of $0 \mathrm{~s}$ (initial), $1 \mathrm{~s}$, and $20 \mathrm{~s}$, respectively. Traces in the fourth row are AP waveforms. In sample traces, AP-evoked voltage-gated $\mathrm{Na}^{+}$currents are inward currents. Time scale: $5 \mathrm{~ms}$. $\boldsymbol{B}$, Time course of amplitudes of inward currents evoked by AP train stimulation at $10 \mathrm{~Hz}($ solid circles, $n=9$ ), $50 \mathrm{~Hz}$ (solid squares, $n=9$ ), and $100 \mathrm{~Hz}$ (solid triangles, $n=9$ ). $\boldsymbol{C}, \boldsymbol{D}$, Similar to $\boldsymbol{A}, \boldsymbol{B}$ except membrane potentials were held at $-84 \mathrm{mV}$. Inward currents were evoked by AP train stimulation at $10 \mathrm{~Hz}(n=9$, solid circles), $50 \mathrm{~Hz}(n=9$, solid squares), and $100 \mathrm{~Hz}(n=9$, solid triangles). E-G, Comparison of amplitudes of inward currents with membrane potentials held at $-75 \mathrm{mV}$ (open bars) and $-84 \mathrm{mV}$ (solid bars). Data were from inward currents at time points of 0,1 , and $20 \mathrm{~s}$. Inward currents were evoked by AP train stimulation at $10 \mathrm{~Hz}(n=9, \boldsymbol{E}), 50 \mathrm{~Hz}(n=9, \boldsymbol{F})$, and $100 \mathrm{~Hz}(n=9, \boldsymbol{G})$. All recordings were performed at NRs at $15^{\circ} \mathrm{C}$. Data represent mean \pm SEM; ns, no significant difference, ${ }^{*} p<0.05,{ }^{* *} p<0.01$, ${ }^{\star \star *} p<0.001$, Student's $t$ test.

and remained unchanged to the end of $10-\mathrm{Hz}$ AP train stimulation. With $50-\mathrm{Hz}$ AP train stimulation, inward current amplitudes were reduced but remained relatively high (Fig. 9C,D). With $100-\mathrm{Hz}$ AP train stimulation, inward currents were further reduced but remained at sizable amplitudes during $20 \mathrm{~s}$ AP train stimulation (Fig. 9C,D).

Comparing inward currents at $15^{\circ} \mathrm{C}$ between the APclamp recordings with holding potentials at -84 and at $-75 \mathrm{mV}$, inward current amplitudes were significantly 
A

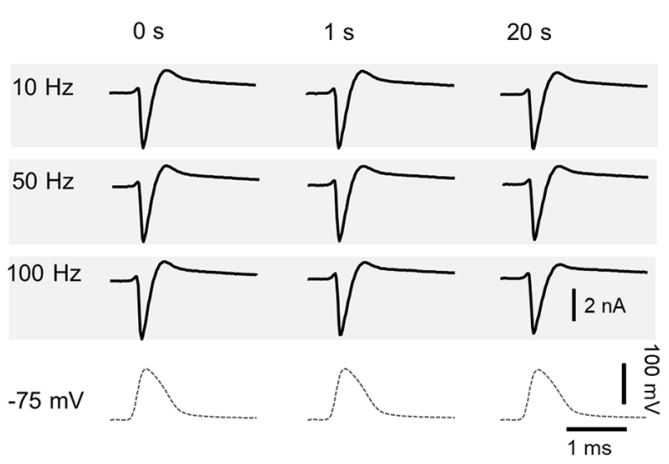

C

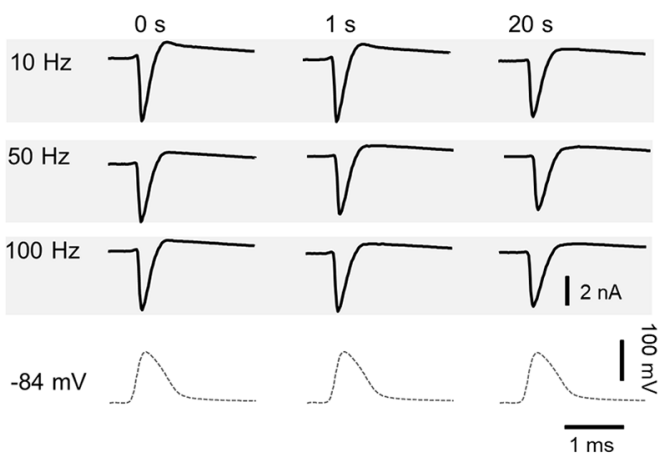

E

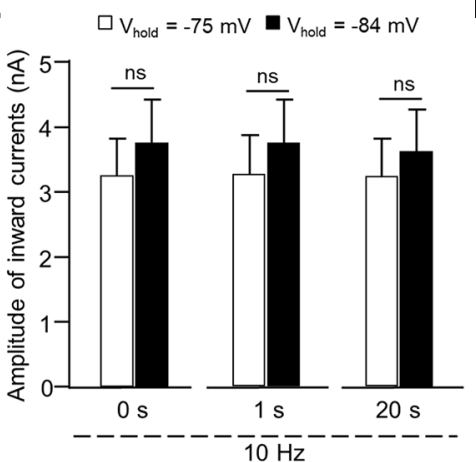

B

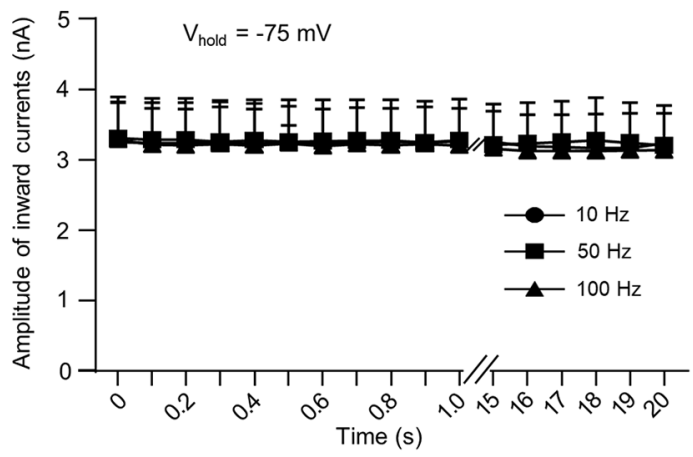

D

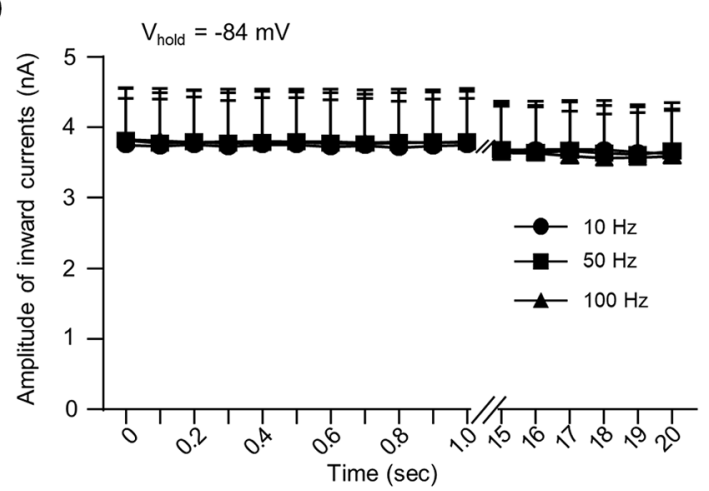

$\mathbf{F}$

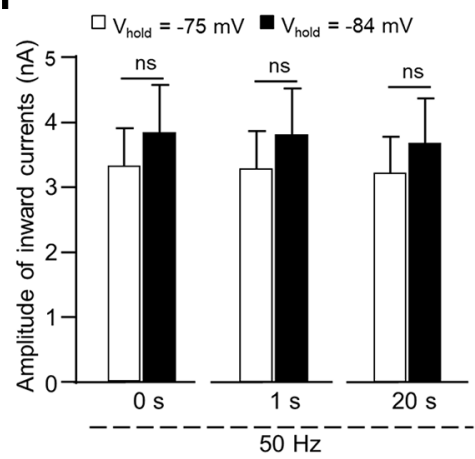

G

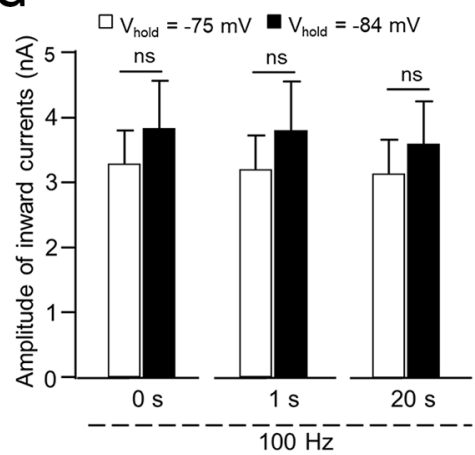

Figure 10. Lack of membrane potential-dependent and frequency-dependent alterations of $\mathrm{AP}$-activated $\mathrm{Na}^{+}$currents at the $\mathrm{NR}$ at $35^{\circ} \mathrm{C}$. $\boldsymbol{A}$, Three sets of sample traces of nodal membrane currents evoked by AP train stimulation at $10 \mathrm{~Hz}$ (first row), $50 \mathrm{~Hz}$ (second row), and $100 \mathrm{~Hz}$ (third row). Nodal membrane potentials were held at $-75 \mathrm{mV}$ and experiments performed at $35^{\circ} \mathrm{C}$. In each row, sample traces on left, middle, and right are the currents evoked at time points of $0 \mathrm{~s}$ (initial), $1 \mathrm{~s}$, and $20 \mathrm{~s}$, respectively. Traces in the fourth row are AP waveforms. Time scale: $1 \mathrm{~ms}$. $\boldsymbol{B}$, Time course of amplitudes of inward currents evoked by AP train stimulation at $10 \mathrm{~Hz}$ (solid circles, $n=5$ ), $50 \mathrm{~Hz}$ (solid squares, $n=5$ ), and $100 \mathrm{~Hz}$ (solid triangles, $n=5$ ). $\boldsymbol{C}, \boldsymbol{D}$, Similar to $\boldsymbol{A}, \boldsymbol{B}$ except membrane potentials were held at $-84 \mathrm{mV}$. Inward currents were evoked by AP train stimulation at $10 \mathrm{~Hz}(n=5$, solid circles), $50 \mathrm{~Hz}(n=5$, solid squares), and $100 \mathrm{~Hz}$ ( $n=5$, solid triangles). $E-G$, Comparison of amplitudes of inward currents at $35^{\circ} \mathrm{C}$ with membrane potentials held at $-75 \mathrm{mV}$ (open bars) and $-84 \mathrm{mV}$ (solid bars). Data were inward currents at time points of 0 , 1, and $20 \mathrm{~s}$. Inward currents were evoked by AP train stimulation at $10 \mathrm{~Hz}(n=5), 50 \mathrm{~Hz}(n=5)$, and $100 \mathrm{~Hz}(n=5)$. All recordings were performed at $\mathrm{NRs}$ at $35^{\circ} \mathrm{C}$. Data represent mean \pm SEM; ns, no significant difference, Student's $t$ test.

larger at the holding potential of $-84 \mathrm{mV}$ than at the holding potential of $-75 \mathrm{mV}$ for all three AP train stimulation frequencies tested (Fig. 9G-I). For example, with $10-\mathrm{Hz}$ $\mathrm{AP}$ train stimulation, inward currents at 1-s time point were $2.163 \pm 0.205 \mathrm{nA}(n=9)$ at the holding potential of $-84 \mathrm{mV}$ and $1.465 \pm 0.123 \mathrm{nA}(n=9)$ at the holding potential of $-75 \mathrm{mV}(p<0.01$; Fig. $9 E)$. With $50-\mathrm{Hz}$ AP train stimulation, inward currents at 1-s time point were $1.495 \pm 0.170 \mathrm{nA}(n=9)$ at the holding potential of $-84 \mathrm{mV}$ and $0.742 \pm 0.120 \mathrm{nA}(n=9)$ at the holding potential of $-75 \mathrm{mV}(p<0.01$; Fig. $9 F)$. With $100-\mathrm{Hz}$ AP train stimulation, inward currents at 1 -s time point were $0.324 \pm 0.133$ $\mathrm{nA}(n=9)$ at the holding potential of $-84 \mathrm{mV}$ and only $0.095 \pm 0.069 \mathrm{nA}(n=9)$ at the holding potential of $-75 \mathrm{mV}$ $(p<0.01$; Fig. 9G). These results suggest that at the cooling temperature of $15^{\circ} \mathrm{C}$, a depolarized nodal RMP partially contributes to lower availability of voltage-gated $\mathrm{Na}^{+}$ channels for high-frequency AP regeneration. 
We next determined the availability of voltage-gated $\mathrm{Na}^{+}$channels at the NR at different AP train stimulation frequencies and different holding potentials at $35^{\circ} \mathrm{C}$ (Fig. 10). As shown in Figure $10 A, B$, at $-75-\mathrm{mV}$ holding potential, inward current amplitude was $3.248 \pm 0.569 \mathrm{nA}(n=5)$ at initial time point ( $0 \mathrm{~s}$ ) and remained unchanged during $10-\mathrm{Hz}$ AP train stimulation. Inward current amplitudes during $50-$ and $100-\mathrm{Hz}$ AP train stimulation were similar to those during 10-Hz AP train stimulation (Fig. 10A,B). At -84-mV holding potential, inward current amplitude was $3.750 \pm 0.662 \mathrm{nA}(n=5)$ at initial time point $(0 \mathrm{~s})$ and remained unchanged during $10-\mathrm{Hz}$ AP train stimulation (Fig. $10 C, D)$. Inward current amplitudes during $50-$ and $100-\mathrm{Hz}$ AP train stimulation was similar to those during $10-\mathrm{Hz}$ AP train stimulation (Fig. 10C,D).

Comparing inward currents at $35^{\circ} \mathrm{C}$ between the recordings with holding potentials at -84 and at $-75 \mathrm{mV}$, inward current amplitudes were not significantly different (Fig. 10E-G). For example, with 10-Hz AP train stimulation, inward currents at 1-s time point were $3.746 \pm$ $0.665 \mathrm{nA}(n=5)$ at the holding potential of $-84 \mathrm{mV}$, and $3.261 \pm 0.595 \mathrm{nA}(n=5)$ at the holding potential of $-75 \mathrm{mV}$ $(p=0.30$; Fig. 10E). With $50-\mathrm{Hz}$ AP train stimulation, inward currents at 1 -s time point were $3.795 \pm 0.716 \mathrm{nA}$ $(n=5)$ at the holding potential of $-84 \mathrm{mV}$, and $3.279 \pm$ $0.576 \mathrm{nA}(n=5)$ at the holding potential of $-75 \mathrm{mV}$ $(p=0.29$; Fig. 10F). With $100-\mathrm{Hz}$ AP train stimulation, inward currents at 1 -s time point were $3.800 \pm 0.749 n A$ $(n=5)$ at the holding potential of $-84 \mathrm{mV}$, and $3.202 \pm$ $0.523 \mathrm{nA}(n=5)$ at the holding potential of $-75 \mathrm{mV}(p=$ 0.27 ; Fig. 10G). These results indicate that, at $35^{\circ} \mathrm{C}$, the availability of voltage-gated $\mathrm{Na}^{+}$channels remain the same at AP train stimulation frequency up to $100 \mathrm{~Hz}$ at either holding potentials.

\section{Discussion}

In the present study, we have shown that cooling temperatures significantly alter intrinsic electrophysiological properties at the NR of $A \beta$-afferent nerves. Furthermore, we have found that cooling temperatures severely compromise the regeneration of high-frequency AP trains at the NR. Importantly, we have demonstrated that thermal $\mathrm{K} 2 \mathrm{P}$ channels at the NR are involved in cooling temperature-induced changes of intrinsic electrophysiological properties and regeneration of high-frequency AP trains at the NRs. Since tactile signals are mainly conveyed by $\mathrm{A} \beta$-afferent nerves in trains of APs, our findings in the present study provide new insights into tactile signaling under cooling temperatures.

We have applied pressure-clamped patch-clamp recording technique in the present study (Kanda et al., $2019,2021)$. This recording technique, developed recently, has allowed us to directly study ion channels and their functions at the NR (Kanda et al., 2019). Previously, our knowledge about ion channels at the NR is mainly from immunochemical studies (Rasband and Peles, 2021), which provides useful but limited information on functions of ion channels at the NR. Using pressureclamped patch-clamp recordings, we have recently shown that the thermal K2P channels TREK1 and TRAAK are clustered at the NR of $\mathrm{A} \beta$-afferent nerves to play a key role in AP repolarization, and high-speed and highfrequency saltatory conduction (Kanda et al., 2019). In the present study, our main focus was on how cooling temperatures impair regeneration of high-frequency AP trains at the NRs. Effects of cooling temperatures on AP conduction velocity at the NR have been reported in our previous study (Kanda et al., 2019). An interesting finding in the present study, consistent with our previous observation (Kanda et al., 2019), is that RMPs at the NR are hyperpolarized at approximately $-84 \mathrm{mV}$ at $35^{\circ} \mathrm{C}$ but are shifted to depolarized levels of approximately $-75 \mathrm{mV}$ at the cooling temperature of $15^{\circ} \mathrm{C}$. In contrast, an earlier study has shown that cooling temperatures did not significantly affect RMPs of the giant axon of the squid (Hodgkin and Katz, 1949). In somatosensory neurons, previous studies show that cooling temperatures can depolarize, have no effect, or hyperpolarize RMPs depending on cell types (Cabanes et al., 2003; Kanda and Gu, 2017). These discrepancies may be because of whether thermal K2P channels are expressed on the nerves being tested. RMPs are known to be set mainly by outward leak $\mathrm{K}^{+}$currents mediated by $\mathrm{K} 2 \mathrm{P}$ channels (Enyedi and Czirják, 2010). In our recordings at the $\mathrm{NR}$ at $35^{\circ} \mathrm{C}$, outward leak $\mathrm{K}^{+}$currents were large in amplitude at the holding potentials of $-72 \mathrm{mV}$. This is consistent with hyperpolarized RMPs at the NR at $35^{\circ} \mathrm{C}$. On the other hand, outward leak $\mathrm{K}^{+}$currents are suppressed at the cooling temperature of $15^{\circ} \mathrm{C}$, which is accompanied by depolarization of RMP at the NR. These results support the idea that the effects of cooling temperatures on RMPs at the $\mathrm{NR}$ are via suppressing activities of thermal K2P channels. The involvement of thermal K2P channels in the depolarized RMPs at cooling temperatures is further supported by thermal K2P activators that reverse the effects of cooling temperatures. Similarly, the increases of membrane input resistance at cooling temperatures could also be attributed to the suppression of thermal K2P activity at the NR. For active membrane properties at the NR, we have shown that cooling temperatures broaden AP widths. $\mathrm{AP}$ widths are $>2$-fold broader at $15^{\circ} \mathrm{C}$ than at $35^{\circ} \mathrm{C}$. Similarly, latencies to AP threshold are $>2$-fold longer at $15^{\circ} \mathrm{C}$ than at $35^{\circ} \mathrm{C}$. The effects on AP widths and latencies to AP threshold by cooling temperatures are at least partially because of the suppression of thermal K2P activity since thermal K2P activator can partially reverse the effect of cooling temperatures. We have recently shown that TREK-1 and TRAAK, rather than voltage-gated $\mathrm{K}^{+}$channels, are principal $\mathrm{K}^{+}$channels involved in driving rapid AP repolarization (Kanda et al., 2019). Thus, suppression of these thermal K2P channels by cooling temperatures would reduce the driving force of AP repolarization leading to AP broadening.

In the present study, we show that cooling temperatures compromise the regeneration of high-frequency AP trains at the NR as is indicated by a decrease of AP success rate. The decrease of AP success rate by cooling temperatures occurs only when APs are elicited by highfrequency train stimulation. Consistently, cooling temperatures have been shown to impair regeneration of high- 
frequency AP trains in human ulnar nerves (Phillips and Matthews, 1993). One mechanism by which cooling temperatures can impair the regeneration of high-frequency AP trains at the NR is direct inhibition of voltage-gated $\mathrm{Na}^{+}$channels by cooling temperatures. Cooling temperatures have been shown to directly slow kinetics and reduce amplitudes of voltage-activated $\mathrm{Na}^{+}$currents in the somas of primary afferent nerves (Sarria et al., 2012), giant axons of squids (Matteson and Armstrong, 1982), and the NR of $A \beta$-afferent nerves as reported in the present study. In addition, subcellular distribution and membrane trafficking of voltage-gated $\mathrm{Na}^{+}$channels (Bao, 2015) may be affected by cooling temperatures, which may be another contributing factor impairing regeneration of high-frequency AP trains at the NR. In the present study, however, the effects of cooling temperatures on regeneration of high-frequency $\mathrm{AP}$ trains at the NR were partially reversed by thermal $\mathrm{K} 2 \mathrm{P}$ activators $\mathrm{BL}, \mathrm{AA}$ and protons. These results suggest that the effects of cooling temperatures on the regeneration of high-frequency AP trains are at least partially mediated by thermal K2P channels. This raises the question of how cooling temperatures via thermal K2P channels affect regeneration of high-frequency AP trains. One contributing factor is that cooling temperatures suppress thermal K2P channels to broaden AP widths, which may prolong inter-spike intervals and reduce AP frequency at the NR. AP broadening leading to reduction of AP firing frequency has been observed in CNS neurons (Nomura et al., 2019). Another contributing factor is that cooling temperatures via suppressing thermal K2P channels prolong latency to AP threshold, which may also result in reduction of AP frequency at the NR. A third contributing factor is that cooling temperatures via suppressing thermal K2P channels depolarize RMPs, which in turn leads to the reduction of AP success rate. At cooling temperatures, a depolarized RMP would promote steady-state inactivation of voltage-gated $\mathrm{Na}^{+}$channels and delay their recovery from inactivation (Kuo and Bean, 1994; Zimmermann et al., 2007). This would reduce the availability of voltage-gated $\mathrm{Na}^{+}$channels for high-frequency AP trains. Consistently, at $15^{\circ} \mathrm{C}$ and with APclamp recording at the NR, inward currents were rapidly reduced following high-frequency AP waveform stimulation when nodal membranes were held at a depolarized level of $-75 \mathrm{mV}$. On the other hand, when membrane potentials were held at a hyperpolarized level of $-84 \mathrm{mV}$, inward currents were significantly higher in comparison with those with nodal membranes held at $-75 \mathrm{mV}$. These results are consistent with previous studies showing that voltage-gated $\mathrm{Na}^{+}$channels undergo steady-state inactivation at cooling temperatures in a membrane potential dependent manner (Zimmermann et al., 2007; Sarria et al., 2012). These results suggest that at cooling temperatures there is an interplay between RMP (via thermal K2P channels) and voltage-gated $\mathrm{Na}^{+}$channels, which limits regeneration of high-frequency AP trains at the NR. A previous study has shown in cultured dorsal root ganglion neurons that at cooling temperatures there was an functional interplay between A-type $\mathrm{K}^{+}$channels and voltagegated $\mathrm{Na}^{+}$channels to control AP firing (Sarria et al.,
2012). In contrast to cooling temperatures, at $35^{\circ} \mathrm{C}$ inward currents were not significantly reduced during high-frequency AP waveform stimulation. This result indicates that at $35^{\circ} \mathrm{C}$ the voltage-gated $\mathrm{Na}^{+}$channels can be recovered from inactivation rapidly during high-frequency AP trains.

Effects of cooling temperatures via thermal K2P channels on high-frequency AP regeneration at the NR and conduction along cutaneous $A \beta$-afferent nerves may have implications in sensory physiology and pathology. Exposing the skin to cooling environment, such as cold winter, can cool cutaneous $A \beta$-afferent nerves to low temperatures. While conduction block of myelinated nerves will occur at temperatures near or below $7^{\circ} \mathrm{C}$ (Franz and Iggo, 1968; Stecker and Baylor, 2009), impairment of regeneration of high-frequency AP train on myelinated nerves would happen at less cold temperatures (Franz and Iggo, 1968). Cutaneous $A \beta$-afferent nerves arising from low threshold mechanical receptors convey tactile signals with train APs in a broad range of frequencies. Tactile functions would be compromised if regeneration of high-frequency AP trains at the NR of $A \beta$-afferent nerves are impaired. Indeed, cooling temperatures can lead to poor acuity of tactile discrimination because of the impairment of regeneration of high-frequency AP trains on ulnar nerves at cooling temperatures in humans (Phillips and Matthews, 1993). In addition, the analgesic effect of cooling (Koç et al., 2006) may be partially attributed to the cooling-induced impairment of high-frequency AP trains in nociceptive A-afferent nerves. Cooling temperatures via thermal K2P channels on high-frequency $\mathrm{AP}$ regeneration and conduction on $A \beta$-afferent nerves may also have implications in sensory dysfunctions seen in patients with peripheral neuropathy.

\section{References}

Bao $L$ (2015) Trafficking regulates the subcellular distribution of voltage-gated sodium channels in primary sensory neurons. Mol Pain 11:61.

Bauer CK, Calligari P, Radio FC, Caputo V, Dentici ML, Falah N, High F, Pantaleoni F, Barresi S, Ciolfi A, Pizzi S, Bruselles A, Person R, Richards S, Cho MT, Claps Sepulveda DJ, Pro S, Battini R, Zampino G, Digilio MC, et al. (2018) Mutations in KCNK4 that affect gating cause a recognizable neurodevelopmental syndrome. Am J Hum Genet 103:621-630.

Boullerne Al (2016) The history of myelin. Exp Neurol 283:431-445.

Brohawn SG, Wang W, Handler A, Campbell EB, Schwarz JR, MacKinnon $R$ (2019) The mechanosensitive ion channel TRAAK is localized to the mammalian node of Ranvier. Elife 8:e50403.

Cabanes C, Viana F, Belmonte C (2003) Differential thermosensitivity of sensory neurons in the guinea pig trigeminal ganglion. $J$ Neurophysiol 90:2219-2231.

Caldwell JH, Schaller KL, Lasher RS, Peles E, Levinson SR (2000) Sodium channel $\mathrm{Na}(\mathrm{v}) 1.6$ is localized at nodes of Ranvier, dendrites, and synapses. Proc Natl Acad Sci USA 97:5616-5620.

Chiu SY, Ritchie JM (1980) Potassium channels in nodal and internodal axonal membrane of mammalian myelinated fibres. Nature 284:170-171.

Devaux J, Alcaraz G, Grinspan J, Bennett V, Joho R, Crest M, Scherer SS (2003) Kv3.1b is a novel component of CNS nodes. J Neurosci 23:4509-4518.

Devaux JJ, Kleopa KA, Cooper EC, Scherer SS (2004) KCNQ2 is a nodal K+ channel. J Neurosci 24:1236-1244. 
Enyedi P, Czirják G (2010) Molecular background of leak K+ currents: two-pore domain potassium channels. Physiol Rev 90:559605.

Franz DN, Iggo A (1968) Conduction failure in myelinated and nonmyelinated axons at low temperatures. J Physiol 199:319-345.

Goldstein SA, Bayliss DA, Kim D, Lesage F, Plant LD, Rajan S (2005) International Union of Pharmacology. LV. Nomenclature and molecular relationships of two-P potassium channels. Pharmacol Rev 57:527-540.

Hodgkin AL, Katz B (1949) The effect of temperature on the electrical activity of the giant axon of the squid. J Physiol 109:240-249.

Huxley AF, Stampfli R (1949) Evidence for saltatory conduction in peripheral myelinated nerve fibres. J Physiol 108:315-339.

Kanda H, Gu JG (2017) Effects of cold temperatures on the excitability of rat trigeminal ganglion neurons that are not for cold sensing. J Neurochem 141:532-543.

Kanda H, Ling J, Tonomura S, Noguchi K, Matalon S, Gu JG (2019) TREK- 1 and TRAAK are principal $\mathrm{K}(+)$ channels at the nodes of Ranvier for rapid action potential conduction on mammalian myelinated afferent nerves. Neuron 104:960-971.e7.

Kanda H, Tonomura S, Dai Y, Gu JG (2021) Protocol for pressureclamped patch-clamp recording at the node of Ranvier of rat myelinated nerves. STAR Protoc 2:100266.

Kang D, Choe C, Kim D (2005) Thermosensitivity of the two-pore domain K+ channels TREK-2 and TRAAK. J Physiol 564:103-116.

Kim Y, Bang H, Gnatenco C, Kim D (2001) Synergistic interaction and the role of $\mathrm{C}$-terminus in the activation of TRAAK $\mathrm{K}+$ channels by pressure, free fatty acids and alkali. Pflugers Arch 442:64-72.

Koç M, Tez M, Yoldaş O, Dizen H, Göçmen E (2006) Cooling for the reduction of postoperative pain: prospective randomized study. Hernia 10:184-186.

Kuo CC, Bean BP (1994) Na+ channels must deactivate to recover from inactivation. Neuron 12:819-829.

Lillie RS (1925) Factors affecting transmission and recovery in the passive iron nerve model. J Gen Physiol 7:473-507.

Liu PW, Blair NT, Bean BP (2017) Action potential broadening in capsaicin-sensitive DRG neurons from frequency-dependent reduction of Kv3 current. J Neurosci 37:9705-9714.

Llinás R, Sugimori M, Simon SM (1982) Transmission by presynaptic spike-like depolarization in the squid giant synapse. Proc Natl Acad Sci USA 79:2415-2419.

Lotshaw DP (2007) Biophysical, pharmacological, and functional characteristics of cloned and native mammalian two-pore domain K+ channels. Cell Biochem Biophys 47:209-256.

Maingret F, Patel AJ, Lesage F, Lazdunski M, Honoré E (1999) Mechano- or acid stimulation, two interactive modes of activation of the TREK-1 potassium channel. J Biol Chem 274:26691-26696.

Maingret F, Lauritzen I, Patel AJ, Heurteaux C, Reyes R, Lesage F, Lazdunski M, Honoré E (2000) TREK-1 is a heat-activated background K(+) channel. EMBO J 19:2483-2491.
Matteson DR, Armstrong CM (1982) Evidence for a population of sleepy sodium channels in squid axon at low temperature. J Gen Physiol 79:739-758.

Nomura $\mathrm{S}$, Kida $\mathrm{H}$, Hirayama $\mathrm{Y}$, Imoto $\mathrm{H}$, Inoue $\mathrm{T}$, Moriyama $\mathrm{H}$, Mitsushima D, Suzuki M (2019) Reduction of spike generation frequency by cooling in brain slices from rats and from patients with epilepsy. J Cereb Blood Flow Metab 39:2286-2294.

Paintal AS (1965) Effects of temperature on conduction in single vagal and saphenous myelinated nerve fibres of the cat. J Physiol 180:20-49.

Phillips JR, Matthews PB (1993) Texture perception and afferent coding distorted by cooling the human ulnar nerve. J Neurosci 13:2332-2341.

Ranvier LA (1871) Contributions à l'histologie et à la physiologie des nerfs périphériques. Comptes Rendus de l'Académie des Sciences 73:1168-1171.

Ranvier L (1872) Recherches sur l'histologie et la physiologie des nerfs. Archives de Physiologie Normale et Pathologique 4:129149.

Rasband MN, Peles E (2021) Mechanisms of node of Ranvier assembly. Nat Rev Neurosci 22:7-20.

Rhodes KJ, Strassle BW, Monaghan MM, Bekele-Arcuri Z, Matos MF, Trimmer JS (1997) Association and colocalization of the Kvbeta1 and Kvbeta2 beta-subunits with Kv1 alpha-subunits in mammalian brain $\mathrm{K}+$ channel complexes. J Neurosci 17:82468258.

Royal P, Andres-Bilbe A, Ávalos Prado P, Verkest C, Wdziekonski B, Schaub S, Baron A, Lesage F, Gasull X, Levitz J, Sandoz G (2019) Migraine-associated TRESK mutations increase neuronal excitability through alternative translation initiation and inhibition of TREK. Neuron 101:232-245.e6.

Sarria I, Ling J, Gu JG (2012) Thermal sensitivity of voltage-gated $\mathrm{Na}+$ channels and A-type $\mathrm{K}+$ channels contributes to somatosensory neuron excitability at cooling temperatures. J Neurochem 122:1145-1154.

Stecker MM, Baylor K (2009) Peripheral nerve at extreme low temperatures 1: effects of temperature on the action potential. Cryobiology 59:1-11.

Tasaki I (1939) The electro-saltatory transmission of the nerve impulse and the effect of narcosis upon the nerve fiber. J PhysiolLondon 127:211-227.

Viatchenko-Karpinski V, Ling J, Gu JG (2018) Characterization of temperature-sensitive leak $\mathrm{K}(+)$ currents and expression of TRAAK, TREK-1, and TREK2 channels in dorsal root ganglion neurons of rats. Mol Brain 11:40.

Waxman SG (2006) Axonal conduction and injury in multiple sclerosis: the role of sodium channels. Nat Rev Neurosci 7:932-941.

Zimmermann K, Leffler A, Babes A, Cendan CM, Carr RW, Kobayashi J, Nau C, Wood JN, Reeh PW (2007) Sensory neuron sodium channel Nav1.8 is essential for pain at low temperatures. Nature 447:855-858. 